\title{
Bargaining with behavioral players: strategic deception and more trade
}

Citation for published version (APA):

Saran, R. R. S. (2007). Bargaining with behavioral players: strategic deception and more trade. METEOR, Maastricht University School of Business and Economics. METEOR Research Memorandum No. 049 https://doi.org/10.26481/umamet.2007049

Document status and date:

Published: 01/01/2007

DOI:

10.26481/umamet.2007049

Document Version:

Publisher's PDF, also known as Version of record

\section{Please check the document version of this publication:}

- A submitted manuscript is the version of the article upon submission and before peer-review. There can be important differences between the submitted version and the official published version of record.

People interested in the research are advised to contact the author for the final version of the publication, or visit the DOI to the publisher's website.

- The final author version and the galley proof are versions of the publication after peer review.

- The final published version features the final layout of the paper including the volume, issue and page numbers.

Link to publication

\footnotetext{
General rights rights.

- You may freely distribute the URL identifying the publication in the public portal. please follow below link for the End User Agreement:

www.umlib.nl/taverne-license

Take down policy

If you believe that this document breaches copyright please contact us at:

repository@maastrichtuniversity.nl

providing details and we will investigate your claim.
}

Copyright and moral rights for the publications made accessible in the public portal are retained by the authors and/or other copyright owners and it is a condition of accessing publications that users recognise and abide by the legal requirements associated with these

- Users may download and print one copy of any publication from the public portal for the purpose of private study or research.

- You may not further distribute the material or use it for any profit-making activity or commercial gain

If the publication is distributed under the terms of Article $25 \mathrm{fa}$ of the Dutch Copyright Act, indicated by the "Taverne" license above, 
Rene Saran

Bargaining with Behavioral Players:

Strategic Deception and More Trade

$\mathrm{RM} / 07 / 049$

JEL code: C78, D82

\section{METE@R}

Maastricht research school of Economics of TEchnology and ORganizations

Universiteit Maastricht

Faculty of Economics and Business Administration P.O. Box 616

NL - 6200 MD Maastricht

phone : ++31433883830

fax : ++31433884873 


\title{
Bargaining with Behavioral Players: \\ Strategic Deception and More Trade
}

\author{
Rene Saran* \\ Maastricht University, Maastricht, The Netherlands \\ This version: September 2007
}

\begin{abstract}
Previous literature proved the existence of an upper bound on the probability of trade in a bilateral trading problem when the valuations are distributed uniformly on $[0,1]$. This upper bound is achieved in the $\frac{1}{2}$-double auction when the players play the Chatterjee-Samuelson strategies. We introduce behavioral-type players in a $\frac{1}{2}$-double auction preceded by cheap talk. The behavioral-type players always declare a keenness to trade in the cheap-talk stage and play the Chatterjee-Samuelson strategies if they hear the "Keen" message. In equilibrium, the probability of trade between the strategic types increases monotonically as the probability of the behavioral types increases. If the probability of the behavioral types is high enough, the probability of trade between the strategic types is greater than the upper bound.
\end{abstract}

Keywords: Bargaining; Double Auction; Cheap Talk; Incomplete Information; Behavioral Type; Probability of Trade

JEL: C78; D82

\section{Introduction}

In their seminal study of the double auctions, Chatterjee and Samuelson (1983) find a pair of linear strategies that is an equilibrium of the $\frac{1}{2}$-double auction when the valuations of the players are distributed independently and uniformly (We term it the C-S equilibrium).

${ }^{*}$ Email address: r.saran@algec.unimaas.nl; Tel: +31-43-3883763; Fax: +31-43-3884878 
When the valuations of the players are independently and uniformly distributed on [0,1], then Myerson and Satterthwaite (1983) show that the associated C-S equilibrium of the $\frac{1}{2}$-double auction, which we term the $\mathrm{C}-\mathrm{S}^{*}$ equilibrium, achieves both the highest ex-ante gains from trade and the highest ex-ante probability of trade relative to any equilibrium of any trading mechanism. ${ }^{1}$ However, the gains from trade and the probability of trade that are achieved in this equilibrium are much below the level that is first-best, that is, there is not as much trade in equilibrium as desirable. The reason for such an outcome is that the players do not have complete information about each others' valuations. The buyer, for example, has to balance two opposing motivations when she makes a bid, the lower she bids the higher is her payoff if trade does occur but that also lowers the probability that she ends up trading with the seller. The bid that is then optimal for the buyer may be such that even though ex-post the seller's valuation is below her valuation, trade may not occur. ${ }^{2}$

In such situations, players can often communicate before bargaining in order to "reduce" the uncertainty. Farrell and Gibbons (1989) show that adding a cheap-talk stage before playing the $\frac{1}{2}$-double auction can lead to effective communication, where different valuation types of the players choose different messages in equilibrium (We term it the F-G equilibrium). However, the F-G equilibrium has a strictly lower ex-ante probability of trade than the C-S* equilibrium. The reason is that the low valuation types of the buyer and the high valuation types of the seller are willing to take the risk of not trading by communicating their disinclination to trade in the cheap-talk stage for a better price in the bargaining stage. ${ }^{3}$

Experimental studies on the $\frac{1}{2}$-double auction by Radner and Schotter (1989), Valley et al. (2002) and McGinn et al. (2003) confirm that trade occurs according to the predictions of the C-S equilibrium when the players are not allowed to communicate before bargaining. ${ }^{4}$

\footnotetext{
${ }^{1}$ In fact, the C-S equilibrium of the $\frac{1}{2}$-double auction is a second-best as long as the valuations of both players are distributed uniformly and independently on the same interval. However, for instance, if the valuations of the buyer and seller are distributed uniformly and independently on $[1,3]$ and $[0,2]$, respectively, then the C-S equilibrium is not a second-best. In general, Satterthwaite and Williams (1989) show that the $k$-double auctions are not optimal for generic distributions of valuations.

${ }^{2}$ See chapter 5 in Osborne and Rubinstein (1990), Binmore et al. (1992), Kennan and Wilson (1993), Ausubel et al. (2002) and Serrano (2005) for surveys on bargaining with incomplete information.

${ }^{3}$ More generally, the above mentioned result of Myerson and Satterthwaite (1983) implies that, when the valuations of the players are distributed independently and uniformly on $[0,1]$, we cannot achieve a higher probability of trade than that in the C-S* equilibrium by allowing for any form of communication (simultaneous or sequential message exchanges) before the $\frac{1}{2}$-double auction.

${ }^{4}$ Radner and Schotter (1989) find that 'the behavior of the subjects is qualitatively consistent with....linear bidding strategies' (p. 180), although the players in the role of the seller on average played according to the C-S linear strategy, the players in the role of the buyer did not bid as low as in the C-S linear strategy. Valley et al. (2002) report that the bidding behavior of the players in their experiments without communication was "economically" close to the C-S equilibrium strategies.
} 
However, these studies also show that when the players are allowed to communicate "freely" before bargaining, they are able to achieve a much higher probability of trade by using the communication stage to either mutually reveal their valuations, coordinate on a single price or coordinate on mutually bidding equal to their valuations.

Is it possible to bridge the gap between these theoretical and experimental results on the $\frac{1}{2}$-double auction? It is not clear how to duplicate the arbitrary message space allowed in the experiments in a theoretical model and even if it were possible, it would be very complicated to solve for an equilibrium of such a model. However, replicating the increase in the overall probability of trade observed in the experiments in a theoretical model is easy. The experiments suggest that some players act non-strategically by mutually revealing their valuations in the communication stage or coordinating to bid equal to their valuations in the bargaining stage. Adding such non-strategic or behavioral-type of players to the model will provide an exogenous boost to the overall probability of trade. If the proportion of such players is high enough, then the overall probability of trade would be higher than that in the C-S* equilibrium outcome. A more interesting theoretical question is that can the probability of trade among only the strategic-type players be higher than that in the C-S* equilibrium outcome?

Taking a cue from the experiments, suppose a proportion of the players are behavioral type in the sense that they are use the pre-bargaining communication stage to coordinate on bidding "less aggressively" in the bargaining stage. One way to achieve such coordination in the bargaining stage is that the behavioral-type players bid "less aggressively" only if both the players send the same message in the communication stage - e.g. both players must smile or express a keenness to trade as in our model. In the absence of such behavioral types, the low valuation types of the strategic-type buyer and the high valuation types of the strategictype seller would prefer to communicate their disinclination to trade in the cheap-talk stage in the hope of a better price in the bargaining stage, which can reduce the probability of trade among the strategic-type players. However, the possibility that the other player is such a behavioral type could induce even some of these valuation types of the strategic-type players to express a keenness to trade in the cheap-talk stage in the hope that the behavioral-type of the other player would interpret this message to mean "lets coordinate on bidding less aggressively" and thus be deceived into bidding "less aggressively". Such strategic deception could therefore increase the probability of trade among the strategic types. Our model formalizes this idea.

The bargaining model in this paper is a $\frac{1}{2}$-double auction preceded by a cheap-talk stage. 
In the cheap-talk stage, the players (a buyer and a seller) choose to say either "Keen" or "Not Keen". Each player can have one of the two dispositions, strategic type or behavioral type. The valuations of both the players irrespective of their disposition types are distributed uniformly on $[0,1]$. The behavioral types always announce "Keen" in the cheap-talk stage and walk away from trade if they hear the "Not Keen" announcement. If a behavioral type hears the "Keen" announcement from the other player, then she bids according to the C-S* equilibrium strategy.

The assumption about the behavior of the behavioral types is motivated by the above mentioned experimental results that confirm that the players play the C-S equilibrium strategies when they are not allowed to communicate. Since the set of equilibrium strategies of the $\frac{1}{2}$-double auction with uniform priors is uncountable, ${ }^{5}$ these experiments suggest that the C-S* equilibrium might be focal for the players. If the players are allowed limited communication opportunities like in the model outlined above, it is possible that the $\mathrm{C}-\mathrm{S}^{*}$ equilibrium outcome remains focal for some players since in their mind the game with such limited communication opportunities is not really different from the one without communication. Hence, the behavioral-type players play the C-S* strategies, but only if they hear the "right" message of "Keen". The behavioral-type players thus use the cheap-talk stage to coordinate on a bidding behavior that generates the $\mathrm{C}-\mathrm{S}^{*}$ equilibrium outcome.

We show that if the probability that a player is a behavioral type is at least $11 \%$, then in an equilibrium, the ex-ante probability of trade in the event that both players are strategic type is strictly higher than the ex-ante probability of trade in the C-S* equilibrium. Moreover, the ex-ante probability of trade in the event that both players are strategic type is strictly higher than the ex-ante probability of trade in the F-G equilibrium as long as the probability of a player being a behavioral type is positive.

In equilibrium, a strategic-type player faces a trade-off in the cheap-talk stage between a higher probability of trade and a better price in the bargaining stage. Whereas the "Not Keen" announcement gives a better price in the bargaining stage, it also reduces the probability of trade. When the probability of any player being a behavioral type is 0 , large intervals of valuation types of the strategic-type players announce "Not Keen" in equilibrium. This leads to a lower probability of trade than that in the C-S* equilibrium. However, with an increase in the probability of a player being a behavioral type, announcing "Keen" becomes

\footnotetext{
${ }^{5}$ For instance, all valuation types of both the players bidding any price in the interval $[0,1]$ as long as it is individually rational for them to trade at that price is an equilibrium. Leininger et al. (1989) study the class of step-function equilibria and Satterthwaite and Williams (1989) study the class of differentiable equilibria of the $k$-double auction.
} 
more attractive to some valuation types of the strategic-type players who were earlier announcing "Not Keen". Now the "Keen" announcement offers these strategic-type players both a higher probability of trade and a better price when they trade with the behavioral types. This is because a positive measure of valuation types of the behavioral-type players bid "less aggressively" than their strategic counterparts in the continuation game following the "Keen" announcement by both players. Hence, hoping that the other player is a behavioral type who would be deceived into interpreting a "Keen" announcement as "lets coordinate on the C-S* equilibrium bids", more valuation types of the strategic-type players announce "Keen". As the probability of a player being a behavioral type increases, the set of valuation types of the strategic-type players announcing "Keen" increases monotonically. As a result, the probability of trade between the strategic types also increases monotonically and after the probability of a player being a behavioral type crosses the threshold of $11 \%$, it is strictly higher than the probability of trade in the C-S* equilibrium.

Three points must be emphasized. First, in the setup analyzed by Myerson and Satterthwaite (1983), it is theoretically impossible to achieve a higher probability of trade than that in the $\mathrm{C}-\mathrm{S}^{*}$ equilibrium. In their setup, both the players are strategic type and the only incomplete information is with respect to the valuation types of the players. We add uncertainty regarding the behavioral-type players to that setup and therefore it becomes possible to increase the probability of trade among the strategic-type players. Secondly, to increase the probability of trade among the strategic types it is necessary that the behavioral types do not shade/exaggerate too much or too little in the bargaining stage. "Aggressive" bidding by the behavioral types will not induce the strategic types to say "Keen" whereas if the behavioral types bid very close to their valuations then that will induce the strategic types to become "aggressive" following a "Keen" announcement by both players, which will reduce the probability of trade among the strategic types. Finally, our model shows that if pre-play cheap-talk is used by the behavioral-types to coordinate their play - which the experiments suggest is indeed the case - then the strategic-type players will not always use the pre-play cheap-talk to credibly signal their private information; instead, some strategic types will use talk to "masquerade" themselves as behavioral type in order to exploit other behavioral-type players.

Several papers have added uncertainty regarding the behavior of players to explain observed phenomena. Kreps et al. (1982) show that players can cooperate for some periods even in a finitely repeated prisoners' dilemma if there exists a possibility that a player is a "Tit-for-Tat" type. Kreps and Wilson (1982) explain predatory practices by firms by adding 
uncertainty regarding the type of the incumbent firm whereas Milgrom and Roberts (1982) explain the same phenomenon by adding uncertainty regarding the behavior pattern of the incumbent firm. Sobel (1985) studies the influence of honest types in a model of strategic information transmission and Abreu and Gul (2000) study how introducing "irrational" types affects bargaining outcomes. Unlike these papers, we do not deal with the issue of the strategic-type players trying to behave like the behavioral-type players in order to build a reputation over a repeated interaction. The only opportunity to imitate the behavioral types is provided in the cheap-talk stage and, as explained above, some valuation types of the strategic-type players use that opportunity to "masquerade" themselves as behavioral type in order to gain both a better price and a higher probability of trade in the bargaining stage.

We outline the model and solve for the equilibrium in Section 2. We conclude in the third section and relegate proofs to the Appendix.

\section{Model}

There are two players, a buyer (denoted by $b$ ) and a seller (denoted by $s$ ). The seller owns an indivisible object that she would like to trade with the buyer. The players trade using a $\frac{1}{2}$-double auction with a pre-play cheap-talk stage. In the cheap-talk stage, the players simultaneously announce either "Keen" or "Not Keen". If both players announce "Not Keen" then there is no trade. ${ }^{6}$ If at least one player announces "Keen" then the players play the $\frac{1}{2}$-double auction. In the $\frac{1}{2}$-double auction, both players simultaneously bid for the object. The object is traded if and only if the buyer's bid is at least as high as the seller's bid at a price equal to the average of both the bids. Denote the valuations of the buyer and seller by $v_{b}$ and $v_{s}$, respectively, and the bids of the buyer and seller by $t_{b}$ and $t_{s}$, respectively. The buyer's payoff is $v_{b}-\frac{1}{2}\left(t_{b}+t_{s}\right)$, while the seller's payoff is $\frac{1}{2}\left(t_{b}+t_{s}\right)-v_{s}$. Both players get a payoff of 0 if the good is not traded.

A player can have one of the two dispositions, behavioral (denoted by bh) and strategic (denoted by st). The probability that a player is a behavioral type is $\epsilon$, which is independent of the valuation and disposition types of the other player. The valuations of both disposition types of a player are distributed uniformly on $[0,1]$ and are also independent of the other

\footnotetext{
${ }^{6}$ As mentioned by Farrell and Gibbons (1989), this could be because the players get sufficiently discouraged after such announcements and do not show up to bargain in the next stage or that they hold pessimistic beliefs and play the no-trade equilibrium. Note that the players play the no-trade equilibrium because they are pessimistic not about the distributions of valuations but about the distributions of bids.
} 
player's valuation and disposition. Each player privately knows her type (valuation and disposition) but does not know the true type of the other player. The probability $\epsilon$ and the distributions of valuations of the players are common knowledge.

The behavioral types of both the buyer and seller always announce "Keen" in the communication stage. In the continuation game following the "Not Keen" announcement by the buyer (seller), the behavioral-type seller (buyer) is extremely pessimistic about the buyer (seller) and therefore bids 1 (0) irrespective of her valuation. In the continuation game following the "Keen" announcement by the buyer, the behavioral-type seller with valuation below $\frac{3}{4}$ bids $\frac{2}{3} v_{s}+\frac{1}{4}$ and the other behavioral types of the seller bid equal to their valuations. Finally, in the continuation game following the "Keen" announcement by the seller, the behavioral-type buyer with valuation above $\frac{1}{4}$ bids $\frac{2}{3} v_{b}+\frac{1}{12}$ and the other behavioral types of the buyer bid equal to their valuations. This behavior of the behavioral types is also common knowledge.

Chatterjee and Samuelson (1983) focus on a pair of linear strategies that is an equilibrium of the $\frac{1}{2}$-double auction when both players are strategic type and their valuations are distributed independently and uniformly. The following theorem is a restatement of their result.

Theorem 0 (Chatterjee and Samuelson (1983)) Suppose the valuations of the buyer and seller are distributed independently and uniformly on $\left[\underline{v}_{b}, \bar{v}_{b}\right]$ and $\left[\underline{v}_{s}, \bar{v}_{s}\right]$, respectively. If $\frac{2}{3} \underline{v}_{b}+\frac{1}{12} \bar{v}_{b}+\frac{1}{4} \underline{v}_{s}<\frac{2}{3} \bar{v}_{s}+\frac{1}{4} \bar{v}_{b}+\frac{1}{12} \underline{v}_{s}$, then the following bidding strategies are an equilibrium of the $\frac{1}{2}$-double auction:

1. Any valuation type of the buyer with valuation such that $\frac{2}{3} v_{b}+\frac{1}{12} \bar{v}_{b}+\frac{1}{4} \underline{v}_{s}<\frac{3}{4} \underline{v}_{s}+$ $\frac{1}{4} \bar{v}_{b}$ bids equal to her valuation. All other valuation types of the buyer bid equal to $\min \left\{\frac{2}{3} v_{b}+\frac{1}{12} \bar{v}_{b}+\frac{1}{4} \underline{v}_{s}, \frac{2}{3} \bar{v}_{s}+\frac{1}{4} \bar{v}_{b}+\frac{1}{12} \underline{v}_{s}\right\}$.

2. Any valuation type of the seller with valuation such that $\frac{2}{3} v_{s}+\frac{1}{4} \bar{v}_{b}+\frac{1}{12} \underline{v}_{s}>\frac{1}{4} \underline{v}_{s}+$ $\frac{3}{4} \bar{v}_{b}$ bids equal to her valuation. All other valuation types of the seller bid equal to $\max \left\{\frac{2}{3} v_{s}+\frac{1}{4} \bar{v}_{b}+\frac{1}{12} \underline{v}_{s}, \frac{2}{3} \underline{v}_{b}+\frac{1}{12} \bar{v}_{b}+\frac{1}{4} \underline{v}_{s}\right\}$.

We refer to the equilibrium described in Theorem 0 as the C-S equilibrium. When the valuations of the players are distributed uniformly and independently on $[0,1]$, then we refer to the particular C-S equilibrium as the C-S* equilibrium. It is easy to see that the behavioral-type player in this paper bids according to the C-S* equilibrium strategy when the other player announces "Keen".

We restrict attention to a set of equilibria that we term as Monotonic-Symmetric. 
Definition 1 In a Monotonic-Symmetric equilibrium, all valuation types of the strategictype buyer with valuations above y say "Keen" and all other valuation types of the strategictype buyer say "Not Keen" whereas all valuation types of the strategic-type seller with valuations below $(1-y)$ say "Keen" and all other valuation types of the strategic-type seller say "Not Keen".

Monotonicity in equilibrium has the appeal that the "Keen" announcement is used by the players to communicate their keenness to trade and hence high valuation types of the strategic-type buyer and low valuation types of the strategic-type seller send "Keen" messages. The motivation behind the symmetric requirement in equilibrium is the symmetry of the game.

Farrell and Gibbons (1989) study the model outlined above when $\epsilon=0$, that is, when both the players are only strategic type (We term it the F-G model). With only the strategic types, there always exist a babbling equilibrium in which talk is ignored. However, an immediate consequence of adding the behavioral types is that talk will never be ignored by the strategic types in equilibrium. The "Not Keen" announcement implies that the player is a strategic type whereas the "Keen" announcement implies that with probability greater than or equal to $\epsilon$, the player is a behavioral type. Therefore, there does not exist a babbling equilibrium in the model with the behavioral types.

The information transmitted through talk is credible in a Monotonic-Symmetric equilibrium of the F-G model. In equilibrium, each claim has a precise meaning, "My valuation is above (below) a", because only a valuation type of a player with valuation above (below) $a$ claims that her valuation is above (below) $a$. However, in our model with the behavioraltype players, only the message "Not Keen" is credible. Only the strategic-type buyer with valuation below $y$ and the strategic-type seller with valuation above $1-y$ announce "Not Keen" in equilibrium and thus the strategic-type of the other player can precisely interpret this message. Information is not credibly revealed by the message "Keen" as it does not have a precise meaning in equilibrium like before. Now, when the strategic-type seller hears the message "Keen", it can have two interpretations, either the buyer is behavioral type or the buyer is strategic type with a valuation greater than $y$.

Farrell and Gibbons (1989) further restrict their analysis to a subset of the MonotonicSymmetric equilibria of the F-G model where the equilibrium strategies of the players in the second-stage continuation games along the equilibrium path are restricted to equal the C-S equilibrium strategies wherever possible; if not possible, then the strategies are restricted to the one-step equilibrium strategies with price equal to $\frac{1}{2}$. We denote their restriction on the 
second-stage equilibrium strategies of the players by $\mathcal{R}$ and call an equilibrium of the F-G model Monotonic-Symmetric- $\mathcal{R}$ if it is Monotonic-Symmetric and it satisfies $\mathcal{R}$.

Farrell and Gibbons (1989) show that in the F-G model, there are two MonotonicSymmetric- $\mathcal{R}$ equilibria, one with $y=0$ and other with $y=\frac{34+6 \sqrt{5}}{61}$ (We denote the latter value by $y^{F G}$ and call the related equilibrium F-G equilibrium). ${ }^{7}$ The first equilibrium with $y=0$ has the same outcome as the $\mathrm{C}_{-} \mathrm{S}^{*}$ equilibrium. In the second equilibrium, cheap talk is credible and information is revealed. More importantly, in the Monotonic-Symmetric equilibrium with $y=y^{F G}$ in the F-G model, the low valuation types of the buyer and the high valuation types of the seller say "Not Keen" to show their disinclination to trade in the hope of a better price in the ensuing $\frac{1}{2}$-double auction. In contrast, if $\epsilon>0$, then as we will see later in this section, some of these valuation types of the strategic-type players say "Keen" because they want to deceive the behavioral-type players into coordinating on the C-S* equilibrium.

In fact, there is another Monotonic-Symmetric- $\mathcal{R}$ equilibrium with $y=1$ in the F-G model. ${ }^{8}$ Here both players say "Not Keen" and have pessimistic beliefs if they hear "Keen". Notice that in this equilibrium there is no trade. In contrast, the following lemma shows that the introduction of the behavioral types ensures that the strategic-type players always trade with a positive probability in any Monotonic-Symmetric equilibrium outcome.

Lemma 1 If $\epsilon>0$, there cannot exist a Monotonic-Symmetric equilibrium with the ex-ante probability of trade in the event that both players are strategic type equal to 0.

Before we begin to analyze the model, let's fix the notation. $v_{i}, d_{i}$ and $t_{i}$, where $i=b, s$, are respectively the valuation, the disposition and the bid of the player $i$. Let $K$ stand for "Keen" and $N K$ stand for "Not Keen". Let $\left[m_{b}, m_{s}\right]$ denote the continuation game when the buyer's side has announced $m_{b}$ and the seller's side has announced $m_{s}$, where $m_{i} \in\{K, N K\}$. $\sigma_{i}$ denotes the strategy of the strategic-type player $i$ in a continuation game. Of course, the

\footnotetext{
${ }^{7}$ The equilibrium value of $y$ reported by Farrell and Gibbons (1989) should be $\frac{34+6 \sqrt{5}}{61} \approx 0.777318$ instead of 0.795 . Also, there cannot exist a Monotonic-Symmetric- $\mathcal{R}$ equilibrium in the F-G model with $y \in\left(0, \frac{1}{4}\right]$ because in the continuation game following the "Not Keen" announcement by the buyer and the "Keen" announcement by the seller, the buyer with valuation $y$ earns a strictly positive payoff, so that valuation types of the buyer with valuations close enough but greater than $y$ would prefer to say "Not Keen" since their payoff from announcing "Keen" is strictly lower.

${ }^{8}$ Furthermore, symmetry in the cheap-talk stage is not a restriction in the F-G model. Define a Monotonic$\mathcal{R}$ equilibrium in which all valuation types of the buyer with valuations above $x_{b}$ say "Keen" and all other valuation types of the buyer say "Not Keen" while all valuation types of the seller with valuations below $z_{s}$ say "Keen" and all other valuation types of the seller say "Not Keen" and which satisfies the restriction $\mathcal{R}$. It can be shown that in the F-G model, the set of Monotonic- $\mathcal{R}$ equilibrium outcomes equals the set of Monotonic-Symmetric- $\mathcal{R}$ equilibrium outcomes.
} 
domain of $\sigma_{i}$ will differ in different continuation games. It should be clear from the context. Let $G_{i}$ denote the distribution of bids induced by $\sigma_{i}$. For a given strategy of player $j$, let $U_{i}\left(v_{i},\left[m_{b}, m_{s}\right]\right)$ be the expected payoff of the strategic-type player $i$ with valuation type $v_{i}$ in the continuation game $\left[m_{b}, m_{s}\right]$ when she bids optimally in that continuation game and let $U_{i}\left(v_{i},\left[m_{b}, m_{s}\right] \mid d_{j}\right)$ be the expected payoff of the strategic-type player $i$ with valuation type $v_{i}$ in the event that player $j$ is of disposition type $d_{j}$ when she bids optimally in the continuation game $\left[m_{b}, m_{s}\right]$.

\subsection{Equilibrium}

We begin the analysis of the model by looking for a particular class of equilibria, termed as Monotonic-Symmetric- $\mathcal{R}^{*}$. This class of equilibria is a subset of the Monotonic-Symmetric equilibria of the model where the strategies of the strategic-type players in the continuation games along the equilibrium path are restricted according to the restriction $\mathcal{R}^{*}$. $\mathcal{R}^{*}$ is a generalization of the restriction $\mathcal{R}$ used by Farrell and Gibbons (1989) to prove the effectiveness of cheap talk in bargaining. According to $\mathcal{R}^{*}$, the strategies of the strategic-type players in the $[K, N K]$ or the $[N K, K]$ continuation games are restricted to equal the $\mathrm{C}-\mathrm{S}$ equilibrium strategies. Lemma 2 proves that it is indeed sequentially rational for the strategic-type players to play the C-S equilibrium strategies in these continuation games.

Lemma 2 In the continuation game $[K, N K]$ along a Monotonic-Symmetric equilibrium path, it is sequentially rational for the strategic types to bid according to the $C$-S equilibrium strategies of the $\frac{1}{2}$-double auction when the valuations of the buyer and seller are distributed uniformly and independently on $[y, 1]$ and $[1-y, 1]$, respectively. Similarly, in the continuation game $[N K, K]$ along a Monotonic-Symmetric equilibrium path, it is sequentially rational for the strategic types to bid according to the $C$-S equilibrium strategies of the $\frac{1}{2}$-double auction when the valuations of the buyer and seller are distributed uniformly and independently on $[0, y]$ and $[0,1-y]$, respectively.

Similarly, whenever possible, $\mathcal{R}^{*}$ requires that the strategic-type players play the C-S equilibrium strategies in the $[K, K]$ continuation game along a Monotonic-Symmetric equilibrium path. It is, however, not always sequentially rational for the strategic-type players to play the C-S equilibrium strategies in this continuation game. Playing the C-S equilibrium strategies is sequentially rational if and only if $y \leq \frac{1}{4}$ or $\frac{1}{4}<y<\frac{5}{8}$ and $\epsilon$ is small enough. In all other cases, $\mathcal{R}^{*}$ restricts the strategies of the strategic-type players in the $[K, K]$ continuation game to equal, if possible, "generalized" versions of the C-S equilibrium strategies; if 
not possible, the strategies equal "generalized" versions of the one-step equilibrium strategies with price equal to $\frac{1}{2}$. Lemma 3 in the Appendix details these sequentially rational strategies of the strategic-type players in the $[K, K]$ continuation game. In this section, we list only Part 3 of Lemma 3. This is because for small values of $\epsilon$, all Monotonic-Symmetric- $\mathcal{R}^{*}$ equilibria with $y \neq 0$ are such that $y$ is greater than $\frac{5}{8}$ (see Proposition 2 ).

Lemma 3 (Part 3 only, full version is in the Appendix) Consider the $[K, K]$ continuation game along a Monotonic-Symmetric equilibrium path. Define $\tilde{\epsilon}=\frac{\epsilon}{\epsilon+(1-\epsilon)(1-y)}$. If $y \geq \frac{5}{8}$ and

(a) if $\epsilon<\frac{8(1-y)}{17-8 y}$, then it is sequentially rational for the strategic types to bid according to the one-step equilibrium with price equal to $\frac{1}{2}$.

(b) if $\frac{8(1-y)}{17-8 y} \leq \epsilon \leq \frac{8(1-y)}{16 y-7}$, then the following strategies for the strategic types are sequentially rational:

- For the strategic-type buyer,

$$
\sigma_{b}\left(v_{b}\right)=\left\{\begin{array}{cc}
\frac{2}{3} v_{b}+\frac{11}{36}-\frac{2}{9 \tilde{\epsilon}} & \text { if } v_{b} \geq \frac{7}{24}+\frac{1}{3 \tilde{\epsilon}} \\
\frac{1}{2} & \text { if } y \leq v_{b}<\frac{7}{24}+\frac{1}{3 \tilde{\epsilon}}
\end{array}\right.
$$

- For the strategic-type seller,

$$
\sigma_{s}\left(v_{s}\right)=\left\{\begin{array}{cc}
\frac{2}{3} v_{s}+\frac{1}{36}+\frac{2}{9 \tilde{\epsilon}} & \text { if } v_{s} \leq \frac{17}{24}-\frac{1}{3 \tilde{\epsilon}} \\
\frac{1}{2} & \text { if } \frac{17}{24}-\frac{1}{3 \tilde{\epsilon}}<v_{s} \leq 1-y
\end{array}\right.
$$

(c) if $\epsilon>\frac{8(1-y)}{16 y-7}$, then the following strategies for the strategic types are sequentially rational:

- For the strategic-type buyer, $\sigma_{b}\left(v_{b}\right)=\frac{2}{3} v_{b}+\frac{11}{36}-\frac{2}{9 \tilde{\epsilon}}$.

- For the strategic-type seller, $\sigma_{s}\left(v_{s}\right)=\frac{2}{3} v_{s}+\frac{1}{36}+\frac{2}{9 \tilde{\epsilon}}$.

Figure 1 shows these sequentially rational strategies of the strategic types in the $[K, K]$ continuation game for different values of $\epsilon$ in a Monotonic-Symmetric equilibrium with $y>\frac{5}{8}$. These linear strategies converge to the $\mathrm{C}_{-} \mathrm{S}^{*}$ equilibrium strategies as $\epsilon \rightarrow 1$ and converge to the one-step equilibrium with price equal to $\frac{1}{2}$ as $\epsilon \rightarrow 0$. If $\epsilon=0$ and all valuation types of the strategic-type seller are bidding equal to $\frac{1}{2}$, then it is sequentially rational for all valuation types of the strategic-type buyer to bid $\frac{1}{2}$ and vice versa. As $\epsilon$ increases, the likelihood that 
the other player is bidding according to the C-S* equilibrium strategy increases and thus it is rational to bid closer to one's C-S* equilibrium strategy.

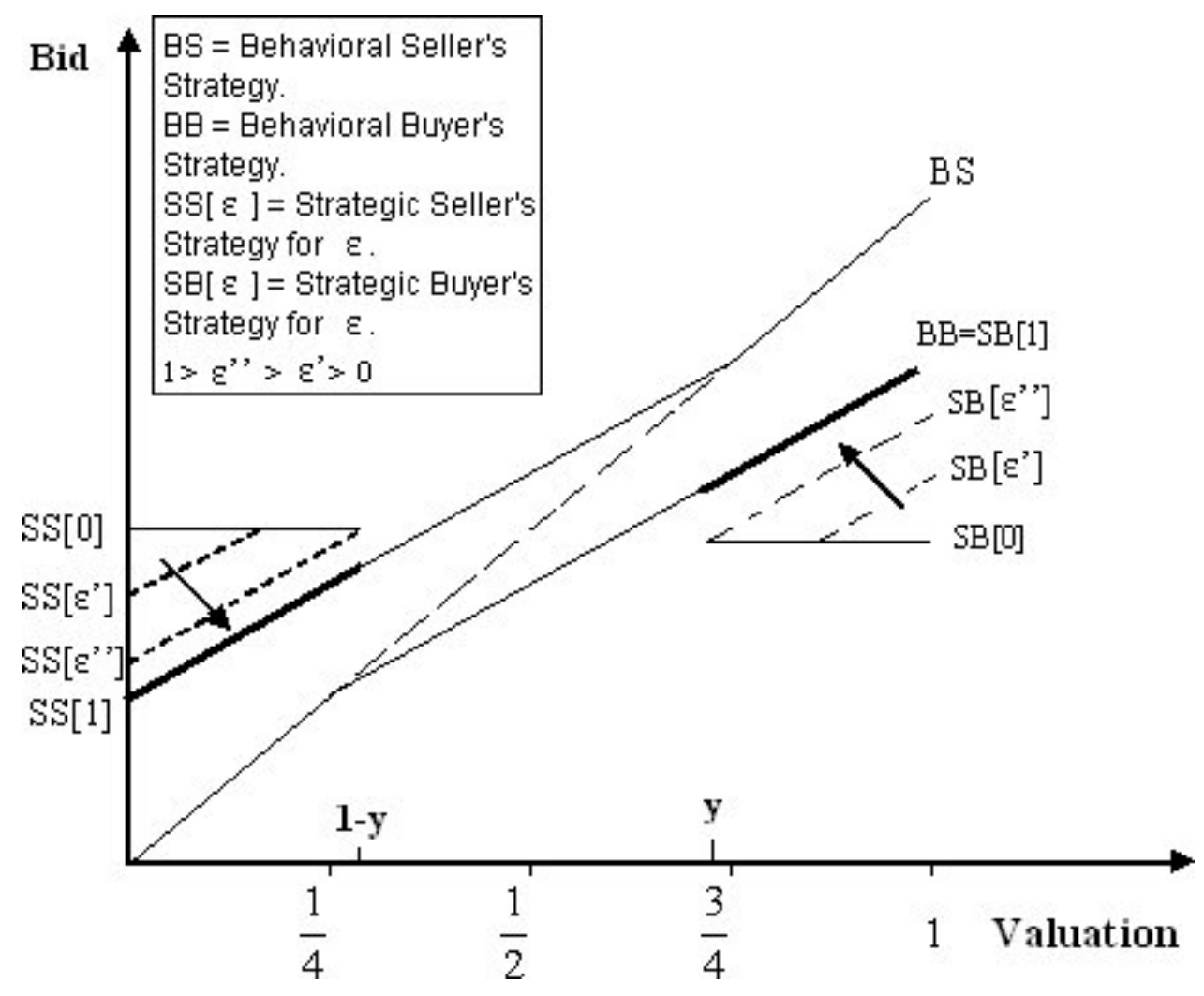

Figure 1: Sequentially rational strategies for the strategic types in the $[K, K]$ continuation game for different values of $\epsilon$ in a Monotonic-Symmetric Equilibrium with $y>\frac{5}{8}$.

We are ready to define a Monotonic-Symmetric- $\mathcal{R}^{*}$ equilibrium.

Definition 2 An equilibrium of the model is called Monotonic-Symmetric- $\mathcal{R}^{*}$ if it is Monotonic-Symmetric and if the strategies of the strategic types in the continuation games along the equilibrium path are restricted to those in Lemma 2 and Lemma 3.

A necessary condition for a Monotonic-Symmetric- $\mathcal{R}^{*}$ equilibrium to exist is that the strategic-type buyer with valuation $y$ must be indifferent between saying "Keen" and "Not Keen". That is,

$$
((1-\epsilon)(1-y)+\epsilon) U_{b}(y,[K, K])+(1-\epsilon) y U_{b}(y,[K, N K])=(1-\epsilon)(1-y) U_{b}(y,[N K, K])
$$


This reduces to,

$$
\begin{aligned}
& (1-\epsilon)\left[(1-y) U_{b}(y,[K, K] \mid s t)+y U_{b}(y,[K, N K])-(1-y) U_{b}(y,[N K, K])\right] \\
+ & \epsilon U_{b}(y,[K, K] \mid b h)=0
\end{aligned}
$$

To see this, first note that the equilibrium-payoff of the strategic-type buyer must be weakly increasing in her valuation, otherwise a higher valuation type can deviate to the strategy of a lower valuation type and get a strictly better payoff. Now, suppose that in equilibrium, the strategic-type buyer with valuation $y$ gets $\delta$ more by saying "Keen" than "Not Keen". Then all valuation types of the strategic-type buyer with valuations in $(y-\delta, y)$ will also prefer to say "Keen". This is because if after saying "Keen", they bid equal to the strategic-type buyer with valuation $y$ then they get a strictly higher payoff than their respective equilibriumpayoffs. Similarly, in equilibrium, the strategic-type seller with valuation $1-y$ must be indifferent between the two announcements. These conditions will be used repeatedly in the proofs.

The next proposition proves that there always exists a Monotonic-Symmetric- $\mathcal{R}^{*}$ equilibrium. This equilibrium is such that all valuation types of both the strategic-type players announce "Keen" in the cheap-talk stage and then play the C-S* equilibrium strategies in the $[K, K]$ continuation game. Thus, this equilibrium has the same outcome as the C-S* equilibrium.

Proposition 1 For all $\epsilon \geq 0$, there exists a Monotonic-Symmetric- $\mathcal{R}^{*}$ equilibrium with $y=0$.

Since the Monotonic-Symmetric- $\mathcal{R}^{*}$ equilibrium with $y=0$ has the same outcome as the $\mathrm{C}-\mathrm{S}^{*}$ equilibrium, we concentrate on the set of Monotonic-Symmetric- $\mathcal{R}^{*}$ equilibria with $y \neq 0$. The next proposition proves that for small $\epsilon$, there indeed exists a MonotonicSymmetric- $\mathcal{R}^{*}$ equilibrium with $y \neq 0$. Moreover, for each of those small $\epsilon$, this equilibrium is unique in the sense that there does not exist any other value of $y \neq 0$ which can be sustained as a Monotonic-Symmetric- $\mathcal{R}^{*}$ equilibrium for that $\epsilon$. It also shows that the value of $y_{\epsilon}$ decreases as $\epsilon$ increases in the interval $\left(0, \frac{244-36 \sqrt{5}}{829}\right)$, with $y_{\epsilon} \rightarrow y^{F G}$ as $\epsilon \rightarrow 0$ and $y_{\epsilon} \rightarrow \frac{5+\sqrt{5}}{10}$ as $\epsilon \rightarrow \frac{244-36 \sqrt{5}}{829} .9$

Proposition 2 For all $\epsilon \in\left(0, \frac{244-36 \sqrt{5}}{829}\right)$, there exists a unique $y_{\epsilon} \neq 0$ such that the game has a Monotonic-Symmetric- $\mathcal{R}^{*}$ equilibrium with $y=y_{\epsilon}$.

$9 \frac{244-36 \sqrt{5}}{829} \approx 0.197227$ and $\frac{5+\sqrt{5}}{10} \approx 0.723607$. 


\subsection{Comparison of Monotonic-Symmetric- $\mathcal{R}^{*}$ equilibria with C-S* and F-G equilibria}

If ex-ante there are no behavioral types, Myerson and Satterthwaite (1983) prove that the C$\mathrm{S}^{*}$ equilibrium of the $\frac{1}{2}$-double auction attains both the highest ex-ante probability of trade and the highest gains from trade relative to any equilibrium of any trading mechanism. In the same setup, if the players trade using instead the F-G model, then the ex-ante probability of trade in the F-G equilibrium is strictly lower than that in the C-S* equilibrium. We have added uncertainty regarding the behavioral types to the F-G model and wish to study how this uncertainty affects the behavior of the strategic types. Does the behavior of the strategic types change so much so that in the event that both players are indeed strategic, they trade more often than if ex-ante there were no behavioral types? To answer this question, we compare the ex-ante probabilities of trade in the C-S* and F-G equilibria and the ex-ante probability of trade in the event that both players are strategic type in the MonotonicSymmetric- $\mathcal{R}^{*}$ equilibrium specified in Proposition 2. ${ }^{10}$

The ex-ante probability of trade in the C-S* equilibrium is $\frac{9}{32}=0.28125$ and in the F-G equilibrium it is $\frac{3}{2} y^{F G}\left(1-y^{F G}\right)$, which is approximately 0.2596 . A simple calculation shows that for the Monotonic-Symmetric- $\mathcal{R}^{*}$ equilibrium in Proposition 2, the ex-ante probability of trade in the event that players are strategic type is given by $\frac{3}{2} y_{\epsilon}\left(1-y_{\epsilon}\right)$.

Proposition 3 For all $\epsilon \in\left(0, \frac{244-36 \sqrt{5}}{829}\right)$, the unique Monotonic-Symmetric- $\mathcal{R}^{*}$ equilibrium with $y \neq 0$ has a higher ex-ante probability of trade in the event that both players are strategic type than the ex-ante probability of trade in the F-G equilibrium.

Proof: In the Monotonic-Symmetric- $\mathcal{R}^{*}$ equilibrium corresponding to such a value of $\epsilon$, the value $y_{\epsilon}$ satisfies $y_{\epsilon}<y^{F G}$ and $y_{\epsilon}>\frac{5+\sqrt{5}}{10}>\frac{1}{2}$. Therefore, $\frac{3}{2} y_{\epsilon}\left(1-y_{\epsilon}\right)>\frac{3}{2} y^{F G}\left(1-y^{F G}\right)$.

When $\epsilon=0$, all valuation types of the strategic-type buyer with valuations below $y^{F G}$ announce "Not Keen" in equilibrium. However, as $\epsilon$ becomes positive, though the strategictype seller is still bidding $\frac{1}{2}$ in the $[K, K]$ continuation game, now there exist valuation types of the behavioral-type seller who bid strictly below $\frac{1}{2}$ in that continuation game. This induces some valuation types of the strategic-type buyer with valuations below $y^{F G}$ to say "Keen". Similarly, some valuation types of the strategic-type seller with valuations above $1-y^{F G}$ now prefer to say "Keen". More valuation types of the strategic-type players saying

\footnotetext{
${ }^{10}$ Another comparison could be of the ex-ante gains from trade. It can be shown that if $\epsilon \gtrsim 0.1642$, then the ex-ante gains form trade in the event that both players are strategic type in the equilibrium in Proposition 2 are greater than the ex-ante gains from trade in the C-S* equilibrium.
} 
"Keen" in the cheap-talk stage positively affects the probability of trade among the strategic types in two ways. Firstly, the valuation types of the strategic-type players who change their announcement from "Not Keen" to "Keen" as $\epsilon$ becomes positive are able to trade irrespective of the other side's announcement whereas when $\epsilon=0$, they could trade only if the other side announced "Keen". This increases the probability of trade among the strategic types in all the three continuation games $[K, K],[K, N K]$ and $[N K, K]$. Secondly, the probability of trade in the $[K, N K]$ and the $[N K, K]$ continuation games further increases as the strategic types adjust their sequentially rational strategies in these continuation games. ${ }^{11}$ These two positive effects are clearly seen in Figure 2, which shows the trading regions under the C-S* equilibrium (labeled CS*-TR), F-G equilibrium (labeled FG-TR) and the trading region under the equilibrium of Proposition 2 in the event that both players are strategic type (labeled ST-TR). Therefore, the probability of trade among the strategic types is higher than that in the F-G equilibrium as $\epsilon$ becomes positive.

As $\epsilon$ further increases in the interval $\left(0, \frac{244-36 \sqrt{5}}{829}\right)$, the value of $y_{\epsilon}$ further decreases (see the proof of Proposition 2). As more valuation types of the strategic-type players announce "Keen" with each increase in $\epsilon$, the ex-ante probability of trade among the strategic types keeps increasing. Once $\epsilon$ crosses the threshold of $\frac{11}{101}$, the ex-ante probability of trade among the strategic types becomes strictly higher than the probability of trade in the C-S* equilibrium. These facts are listed in the next two propositions.

Proposition 4 If $\epsilon<\frac{11}{101}$, then the unique Monotonic-Symmetric- $\mathcal{R}^{*}$ equilibrium with $y \neq 0$ has a lower ex-ante probability of trade in the event that both players are strategic type than the ex-ante probability of trade in the $C$ - $S^{*}$ equilibrium.

Proof: For $\epsilon<\frac{11}{101}, y_{\epsilon}>\frac{3}{4}$. This implies that $\frac{3}{2} y_{\epsilon}\left(1-y_{\epsilon}\right)<\frac{9}{32}$.

Proposition 5 If $\frac{244-36 \sqrt{5}}{829}>\epsilon>\frac{11}{101}$, then the unique Monotonic-Symmetric- $\mathcal{R}^{*}$ equilibrium with $y \neq 0$ has a higher ex-ante probability of trade in the event that both players are strategic type than the ex-ante probability of trade in the $C$ - $S^{*}$ equilibrium.

Proof: $\epsilon>\frac{11}{101} \Longrightarrow y_{\epsilon}<\frac{3}{4} \Longrightarrow \frac{3}{2} y_{\epsilon}\left(1-y_{\epsilon}\right)>\frac{9}{32}$

The obvious question that now arises is, what can we say when $\epsilon \geq \frac{244-36 \sqrt{5}}{829}$ ? We know from Proposition 1 that there always exists a Monotonic-Symmetric- $\mathcal{R}^{*}$ equilibrium with $y=0$. Also, in that equilibrium, all strategic types bid according to the C-S* equilibrium

\footnotetext{
${ }^{11}$ The strategic types do not adjust their bids in the $[K, K]$ continuation game and continue to bid $\frac{1}{2}$. This is because for all $\epsilon \in\left(0, \frac{244-36 \sqrt{5}}{829}\right), \epsilon<\frac{8\left(1-y_{\epsilon}\right)}{17-8 y_{\epsilon}}$. See the proof of Proposition 2 for details.
} 


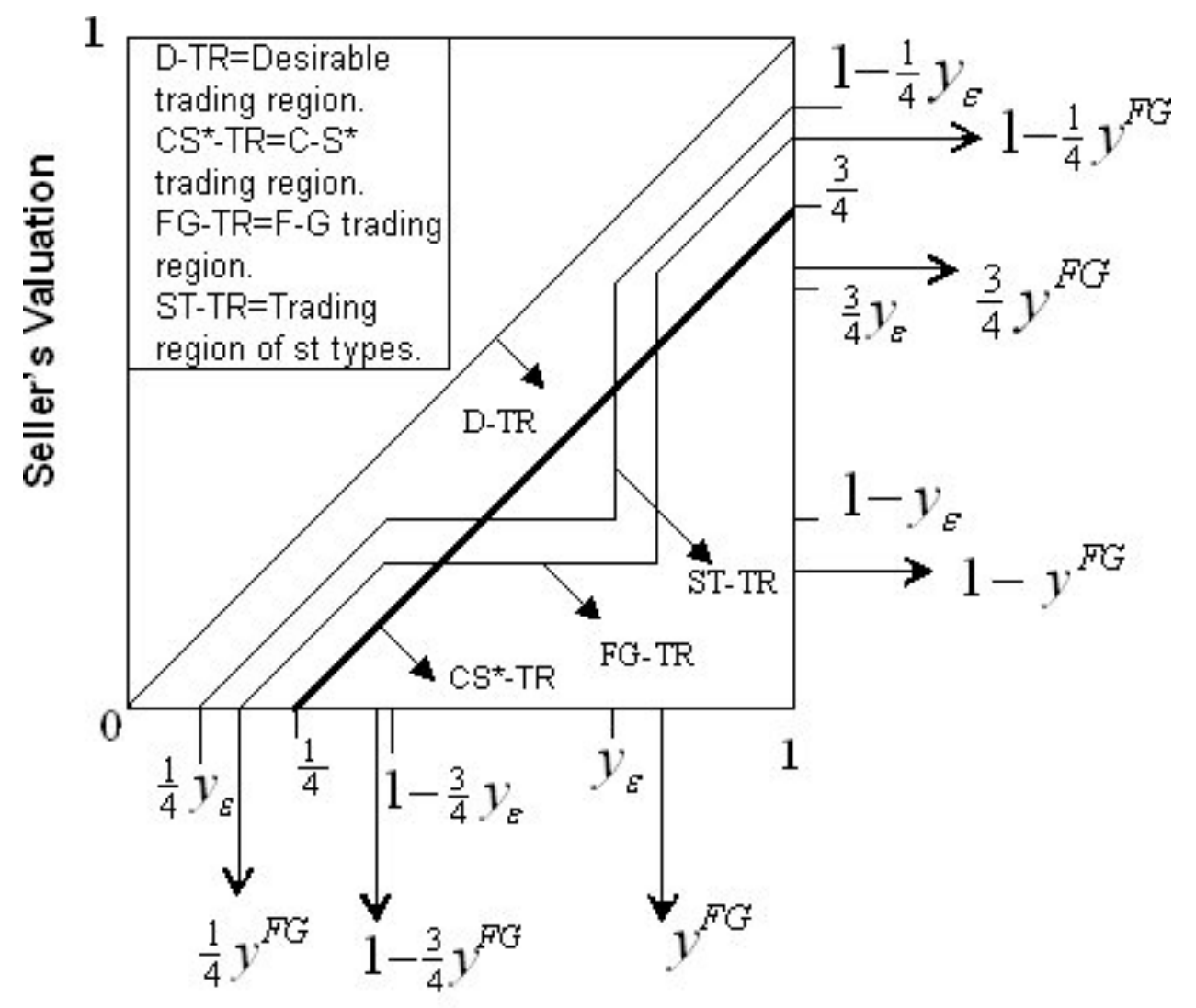

Buyer's Valuation

Figure 2: A comparison of various trading regions.

strategies, and hence, the ex-ante probability of trade in the event that both players are strategic type in that equilibrium is the same as the ex-ante probability of trade in the C-S* equilibrium. We prove in the next proposition that if $\epsilon \in\left[\frac{244-36 \sqrt{5}}{829}, 1\right)$, then any MonotonicSymmetric- $\mathcal{R}^{*}$ equilibrium with $y \neq 0$ must have a strictly higher ex-ante probability of trade among the strategic types than the ex-ante probability of trade in the C-S* equilibrium. ${ }^{12}$

Proposition 6 For $\epsilon \in\left[\frac{244-36 \sqrt{5}}{829}, 1\right)$, any Monotonic-Symmetric- $\mathcal{R}^{*}$ equilibrium with $y \neq 0$ has a higher ex-ante probability of trade in the event that both players are strategic type than the ex-ante probability of trade in the $C$-S $S^{*}$ equilibrium.

\footnotetext{
${ }^{12}$ Though it needs to be proved, we conjecture that for such a large value of $\epsilon$, there exists a MonotonicSymmetric- $\mathcal{R}^{*}$ with $y \neq 0$. From the proof of Proposition 2, we can see that for small values of $\epsilon$, there is a one-to-one relation between $\epsilon$ and $y_{\epsilon}$. This is not surprising given the necessary condition (1). Hence, we expect that this will also hold for large values of $\epsilon$.
} 
Corollary 1 For $\epsilon \in\left[\frac{244-36 \sqrt{5}}{829}, 1\right)$, any Monotonic-Symmetric- $\mathcal{R}^{*}$ equilibrium has at least as high ex-ante probability of trade in the event that both players are strategic type as the ex-ante probability of trade in the $C$ - $S^{*}$ equilibrium.

Proof: Follows from Proposition 6 and the fact that the ex-ante probability of trade among the strategic types in the Monotonic-Symmetric- $\mathcal{R}^{*}$ equilibrium with $y=0$ is the same as the probability of trade in the $\mathrm{C}-\mathrm{S}^{*}$ equilibrium.

Corollary 2 For all $\epsilon>0$, any Monotonic-Symmetric- $\mathcal{R}^{*}$ equilibrium has a strictly higher ex-ante probability of trade in the event both players are strategic type than the ex-ante probability of trade in the F-G equilibrium.

Proof: Follows from Proposition 3 and Proposition 6 and the fact that the ex-ante probability of trade among the strategic types in the Monotonic-Symmetric- $\mathcal{R}^{*}$ equilibrium with $y=0$ is the same as the probability of trade in the $\mathrm{C}-\mathrm{S}^{*}$ equilibrium.

\section{Conclusion}

Myerson and Satterthwaite (1983) prove that it is impossible to attain a higher probability of trade than that in the $\mathrm{C}_{-} \mathrm{S}^{*}$ equilibrium outcome of the $\frac{1}{2}$-double auction. Farrell and Gibbons (1989) show that pre-play cheap talk leads to effective communication but does not improve the probability of trade since some valuation types use talk to credibly signal their disinclination to trade in the hope of a better price in the double auction. We introduced behavioral-type players into a $\frac{1}{2}$-double auction with pre-play communication. The behavioral-type players use the pre-play cheap talk to coordinate on bidding "less aggressively" than their strategic counterparts - in fact such non-strategic behavior is observed in experiments. The behavioral types thus bid "less aggressively" if and only if both players express a keenness to trade. This changes the incentives of some strategic-type players. Instead of using cheap-talk to credibly signal their disinclination to trade, some strategictype players imitate the behavioral types in the cheap-talk stage in the hope that the other player is a behavioral type who would then be deceived into coordinating on bidding "less aggressively". These strategic types thus now express a keenness to trade, which improves the probability of trade among the strategic type players. If the probability that a player is behavioral type is high enough, the probability of trade among the strategic types is higher than that in the $\mathrm{C}-\mathrm{S}^{*}$ equilibrium outcome. 


\section{Acknowledgments}

This paper is based on Chapter 2 of my Ph.D dissertation (Brown University, 2007). I am indebted to my advisor Roberto Serrano for his guidance and suggestions throughout the project. I wish to also thank Pedro Dal Bó for his comments and suggestions.

\section{Appendix}

We provide proofs for only one player to avoid repetition.

Proof of Lemma 1: First, we prove that $y<1$ in any Monotonic-Symmetric equilibrium. Suppose otherwise. Then, for all valuation types of the strategic-type buyer with valuations greater than $\frac{1}{4}$, it is better to deviate in the first stage and say "Keen" because they trade with a positive probability with the behavioral-type seller by announcing "Keen" whereas they get 0 by saying "Not Keen".

Second, consider the continuation game following the "Keen" announcements by both players. In this continuation game, any valuation type of a strategic-type player who does not trade with the strategic type of the other player must bid according to the C-S* equilibrium strategy because her bid maximizes her expected payoff given that she could trade only with the behavioral type of the other player. For instance, the expected payoff of the strategictype buyer with valuation $v_{b}$ who bids $t_{b}$ such that she does not trade with the strategic-type seller equals

$$
\frac{\epsilon}{\epsilon+(1-\epsilon)(1-y)} \int_{\left[0, t_{b}\right]}\left(v_{b}-\frac{1}{2}\left(t_{b}+t_{s}\right)\right) d \tilde{G}_{s}\left(t_{s}\right)
$$

where $\tilde{G}_{s}$ is the distribution of bids induced by the behavioral-type seller in the continuation game. Then, it is optimal for this strategic-type buyer to bid according to the C-S* strategy since the behavioral-type seller bids according to the C-S* strategy. So if no positive measure of the strategic-type players trade in this continuation game, all the strategic-type players must bid according to the C-S* strategy. But that leads to a contradiction since according to the C-S* strategy, the valuation types of the strategic-type buyer with valuations near 1 bid strictly higher than the valuation types of the strategic-type seller with valuations near 0 .

Therefore, in any Monotonic-Symmetric equilibrium, a positive measure of valuation types of the strategic-type players announce "Keen" and in the continuation game following the "Keen" announcements by both players, the probability of trade among the strategictype players is positive. 
Proof of Lemma 2: Suppose along a Monotonic-Symmetric equilibrium path, the buyer's side announces "Keen" and the seller's side announces "Not Keen". Then, it is common knowledge among the strategic-type players that the valuations of the strategic-type buyer and the strategic-type seller are distributed uniformly on $[y, 1]$ and $[1-y, 1]$ respectively.

The strategic-type buyer knows that the seller is strategic type since the seller announced "Not Keen". Hence, if the strategic-type seller bids according to the C-S equilibrium strategy, it is optimal for the strategic-type buyer to also bid according to the C-S equilibrium strategy.

The behavioral-type buyer will bid 0 and so the probability that the strategic-type seller trades with the behavioral-type buyer is 0. Hence, when the strategic-type seller chooses a bid, she maximizes her expected payoff from trading only with the strategic-type buyer. Therefore, if the strategic-type buyer uses the C-S equilibrium strategy, then the expected payoff of the strategic-type seller with valuation $v_{s}$ who bids $t_{s}$ equals,

$$
\left(1-\frac{\epsilon}{\epsilon+(1-\epsilon)(1-y)}\right) \int_{\left[t_{s}, 1\right]}\left(\frac{1}{2}\left(t_{b}+t_{s}\right)-v_{s}\right) d G_{b}\left(t_{b}\right) .
$$

Since the constant is irrelevant in determining the optimal bid, it is also optimal for the strategic-type seller to bid according to the C-S equilibrium strategy. A similar argument completes the proof when the seller's side announces "Keen" and the buyer's side announces "Not Keen".

Lemma 3 Consider the $[K, K]$ continuation game along a Monotonic-Symmetric equilibrium path. Define $\tilde{\epsilon}=\frac{\epsilon}{\epsilon+(1-\epsilon)(1-y)}$.

1. If $y \leq \frac{1}{4}$, then it is sequentially rational for the strategic types to bid according to the $C$-S equilibrium strategies of the $\frac{1}{2}$-double auction when the valuations of the buyer and seller are distributed uniformly and independently on $[y, 1]$ and $[0,1-y]$ respectively.

2. If $\frac{1}{4}<y<\frac{5}{8}$ and

(a) if $\epsilon<\frac{4(1-y)}{8 y+1}$, then it is sequentially rational for the strategic types to bid according to the $C$-S equilibrium strategies of the $\frac{1}{2}$-double auction when the valuations of the buyer and seller are distributed uniformly and independently on $[y, 1]$ and $[0,1-y]$ respectively.

(b) if $\epsilon \geq \frac{4(1-y)}{8 y+1}$, then the following strategies are sequentially rational: ${ }^{13}$

\footnotetext{
${ }^{13}$ Note that $\frac{11}{12}+\frac{1}{3 \tilde{\epsilon}}-y \leq 1 \Longleftrightarrow y+\frac{1}{12}-\frac{1}{3 \tilde{\epsilon}} \geq 0 \Longleftrightarrow \epsilon \geq \frac{4(1-y)}{8 y+1}$. Also, $\frac{11}{12}+\frac{1}{3 \tilde{\epsilon}}-y \geq \frac{5}{4}-y \Longleftrightarrow$ $y+\frac{1}{12}-\frac{1}{3 \tilde{\epsilon}} \leq y-\frac{1}{4} \Longleftrightarrow \tilde{\epsilon} \leq 1 \Longleftrightarrow \epsilon \leq 1$.
} 
- For the strategic-type buyer,

$$
\sigma_{b}\left(v_{b}\right)=\left\{\begin{array}{cc}
\frac{2}{3} v_{b}+\frac{1}{12} & \text { if } v_{b} \leq \frac{5}{4}-y \\
\frac{2}{3}(1-y)+\frac{1}{4} & \text { if } \frac{5}{4}-y \leq v_{b} \leq \frac{11}{12}+\frac{1}{3 \tilde{\epsilon}}-y \\
\frac{2}{3} v_{b}+\frac{11}{36}-\frac{2}{9 \tilde{\epsilon}} & \text { if } v_{b} \geq \frac{11}{12}+\frac{1}{3 \tilde{\epsilon}}-y
\end{array}\right.
$$

- For the strategic-type seller,

$$
\sigma_{s}\left(v_{s}\right)=\left\{\begin{array}{cc}
\frac{2}{3} v_{s}+\frac{1}{36}+\frac{2}{9 \tilde{\epsilon}} & \text { if } v_{s} \leq y+\frac{1}{12}-\frac{1}{3 \tilde{\epsilon}} \\
\frac{2}{3} y+\frac{1}{12} & \text { if } y+\frac{1}{12}-\frac{1}{3 \tilde{\epsilon}} \leq v_{s} \leq y-\frac{1}{4} \\
\frac{2}{3} v_{s}+\frac{1}{4} & \text { if } v_{s} \geq y-\frac{1}{4}
\end{array}\right.
$$

3. If $y \geq \frac{5}{8}$ and

(a) if $\epsilon<\frac{8(1-y)}{17-8 y}$, then it is sequentially rational for the strategic types to bid according to the one-step equilibrium with price equal to $\frac{1}{2}$.

(b) if $\frac{8(1-y)}{17-8 y} \leq \epsilon \leq \frac{8(1-y)}{16 y-7}$, then the following strategies for the strategic types are sequentially rational: ${ }^{14}$

- For the strategic-type buyer,

$$
\sigma_{b}\left(v_{b}\right)=\left\{\begin{array}{cc}
\frac{2}{3} v_{b}+\frac{11}{36}-\frac{2}{9 \tilde{\epsilon}} & \text { if } v_{b} \geq \frac{7}{24}+\frac{1}{3 \tilde{\epsilon}} \\
\frac{1}{2} & \text { if } y \leq v_{b}<\frac{7}{24}+\frac{1}{3 \tilde{\epsilon}}
\end{array}\right.
$$

- For the strategic-type seller,

$$
\sigma_{s}\left(v_{s}\right)=\left\{\begin{array}{cc}
\frac{2}{3} v_{s}+\frac{1}{36}+\frac{2}{9 \tilde{\epsilon}} & \text { if } v_{s} \leq \frac{17}{24}-\frac{1}{3 \tilde{\epsilon}} \\
\frac{1}{2} & \text { if } \frac{17}{24}-\frac{1}{3 \tilde{\epsilon}}<v_{s} \leq 1-y
\end{array}\right.
$$

(c) if $\epsilon>\frac{8(1-y)}{16 y-7}$, then the following strategies for the strategic types are sequentially rational:

- For the strategic-type buyer, $\sigma_{b}\left(v_{b}\right)=\frac{2}{3} v_{b}+\frac{11}{36}-\frac{2}{9 \tilde{\epsilon}}$.

- For the strategic-type seller, $\sigma_{s}\left(v_{s}\right)=\frac{2}{3} v_{s}+\frac{1}{36}+\frac{2}{9 \tilde{\epsilon}}$.

\section{Proof:}

\footnotetext{
${ }^{14}$ Note that $(1-y) \geq \frac{17}{24}-\frac{1}{3 \tilde{\epsilon}} \Longleftrightarrow \frac{7}{24}+\frac{1}{3 \tilde{\epsilon}} \geq y \Longleftrightarrow \epsilon \leq \frac{8(1-y)}{16 y-7}$. Also, $\frac{7}{24}+\frac{1}{3 \tilde{\epsilon}} \leq 1 \Longleftrightarrow \frac{17}{24}-\frac{1}{3 \tilde{\epsilon}} \geq$ $0 \Longleftrightarrow \epsilon \geq \frac{8(1-y)}{17-8 y}$. Finally, $\frac{8(1-y)}{16 y-7} \geq \frac{8(1-y)}{17-8 y} \forall y \geq \frac{5}{8}$.
} 
1. $y \leq \frac{1}{4}$

The C-S strategies are:

- For the strategic-type buyer,

$$
\sigma_{b}\left(v_{b}\right)=\left\{\begin{array}{cl}
\frac{2}{3} v_{b}+\frac{1}{12} & \text { if } v_{b} \geq \frac{1}{4} \\
v_{b} & \text { if } v_{b}<\frac{1}{4}
\end{array}\right.
$$

- For the strategic-type seller,

$$
\sigma_{s}\left(v_{s}\right)=\left\{\begin{array}{cl}
\frac{2}{3} v_{s}+\frac{1}{4} & \text { if } v_{s} \leq \frac{3}{4} \\
v_{s} & \text { if } v_{s}>\frac{3}{4}
\end{array}\right.
$$

Let $\tilde{G}_{s}$ denote the distribution of bids induced by the strategy of the behavioral-type seller. Then, the strategic-type buyer's belief about the distribution of the seller's bid $t_{s}$ is:

- With probability $1-\tilde{\epsilon}$, the seller is strategic type and therefore,

$$
G_{s}\left(t_{s}\right)=\left\{\begin{array}{cc}
\frac{3}{2(1-y)}\left(t_{s}-\frac{1}{4}\right) & \text { if } \frac{1}{4} \leq t_{s} \leq \frac{3}{4} \\
\frac{t_{s}}{1-y} & \text { if } \frac{3}{4} \leq t_{s} \leq 1-y
\end{array}\right.
$$

- With probability $\tilde{\epsilon}$, the seller is behavioral type and therefore,

$$
\tilde{G}_{s}\left(t_{s}\right)=\left\{\begin{array}{cl}
\frac{3}{2}\left(t_{s}-\frac{1}{4}\right) & \text { if } \frac{1}{4} \leq t_{s} \leq \frac{3}{4} \\
t_{s} & \text { if } \frac{3}{4} \leq t_{s} \leq 1
\end{array}\right.
$$

No valuation type of the strategic-type buyer will bid $t_{b}>1-y$. Of course, for any valuation type of the strategic-type buyer, a bid greater than 1 is strictly dominated by the bid equal to 1 . The expected payoff of the strategic-type buyer who bids $t_{b} \in(1-y, 1]$ is

$$
(1-\tilde{\epsilon})\left(v_{b}-\frac{1}{2} t_{b}-\frac{1}{2} \int_{\left[\frac{1}{4}, 1-y\right]} t_{s} d G_{s}\right)+\tilde{\epsilon} \int_{\left[\frac{1}{4}, t_{b}\right]}\left(v_{b}-\frac{1}{2}\left(t_{b}+t_{s}\right)\right) d \tilde{G}_{s} .
$$

The derivative of the above expression with respect to $t_{b}$ is $-(1-\tilde{\epsilon}) \frac{1}{2}+\tilde{\epsilon}\left(v_{b}-\frac{3}{2} t_{b}\right)$, which is negative for all $v_{b}$ since $t_{b}>1-y \geq \frac{3}{4}>\frac{2}{3} v_{b}$. 
If $t_{s} \leq 1-y$, the two distributions $G_{s}$ and $\tilde{G}_{s}$ are the same up to a positive constant $\frac{1}{1-y}$. Since the strategic-type buyer bids $t_{b} \leq 1-y$, her expected payoff is $\left(\frac{1-\tilde{\epsilon}}{1-y}+\tilde{\epsilon}\right) \int_{\left[\frac{1}{4}, t_{b}\right]}\left(v_{b}-\frac{1}{2}\left(t_{b}+t_{s}\right)\right) d \tilde{G}_{s}$. The positive constant $\left(\frac{1-\tilde{\epsilon}}{1-y}+\tilde{\epsilon}\right)$ is irrelevant in determining the optimal bid and we know that when facing a bid distribution $\tilde{G}_{s}$, it is optimal for the strategic-type buyer to bid according to the C-S strategy given above.

2. $\frac{5}{8}>y>\frac{1}{4}$

(a) Suppose $\epsilon<\frac{4(1-y)}{8 y+1}$. We prove that the C-S strategies given below are sequentially rational.

- For the strategic-type buyer,

$$
\sigma_{b}\left(v_{b}\right)=\left\{\begin{array}{cl}
\frac{2}{3} v_{b}+\frac{1}{12} & \text { if } v_{b} \leq \frac{5}{4}-y \\
\frac{2}{3}(1-y)+\frac{1}{4} & \text { if } v_{b} \geq \frac{5}{4}-y
\end{array}\right.
$$

- For the strategic-type seller,

$$
\sigma_{s}\left(v_{s}\right)= \begin{cases}\frac{2}{3} y+\frac{1}{12} & \text { if } v_{s} \leq y-\frac{1}{4} \\ \frac{2}{3} v_{s}+\frac{1}{4} & \text { if } v_{s} \geq y-\frac{1}{4}\end{cases}
$$

Now the strategic-type buyer's belief about the distribution of the seller's bid is:

- With probability $1-\tilde{\epsilon}$ the seller is strategic type and therefore,

$$
G_{s}\left(t_{s}\right)=\left\{\begin{array}{cc}
0 & \text { if } t_{s}<\frac{2}{3} y+\frac{1}{12} \\
\frac{y-\frac{1}{4}}{1-y} & \text { if } t_{s}=\frac{2}{3} y+\frac{1}{12} \\
\frac{3}{2(1-y)}\left(t_{s}-\frac{1}{4}\right) & \text { if } \frac{2}{3} y+\frac{1}{12}<t_{s} \leq \frac{2}{3}(1-y)+\frac{1}{4}
\end{array}\right.
$$

- With probability $\tilde{\epsilon}, t_{s}$ has the distribution function $\tilde{G}_{s}$.

The expected payoff of the strategic-type buyer is $\tilde{\epsilon} \int_{\left[\frac{1}{4}, t_{b}\right]}\left(v_{b}-\frac{1}{2}\left(t_{b}+t_{s}\right)\right) d \tilde{G}_{s}$ when $t_{b}<\frac{2}{3} y+\frac{1}{12}$. Therefore, the optimal bid for the strategic-type buyer equals her C-S bid, which is $\frac{2}{3} v_{b}+\frac{1}{12}$. However, $\frac{2}{3} v_{b}+\frac{1}{12} \geq \frac{2}{3} y+\frac{1}{12}$, a contradiction. Hence, all valuation types of the strategic-type buyer bid at least $\frac{2}{3} y+\frac{1}{12}$. If $t_{b} \geq \frac{2}{3}(1-y)+\frac{1}{4}$, then the first order condition is,

$$
-\frac{1}{2}+\tilde{\epsilon}\left(\frac{3}{2} v_{b}-\frac{9}{4} t_{b}+\frac{11}{16}\right) \leq 0
$$


When the above condition holds with a strict inequality, the constraint must bind. Note that if this is true for the strategic-type buyer with valuation equal to 1 , then it must also be true for all valuation types of the strategic-type buyer with valuations less than 1 . To ensure that the highest valuation type of the strategictype buyer bids $\frac{2}{3}(1-y)+\frac{1}{4}$ we must have, $-\frac{1}{2}+\tilde{\epsilon}\left(\frac{3}{2}-\frac{9}{4}\left(\frac{2}{3}(1-y)+\frac{1}{4}\right)+\frac{11}{16}\right)<$ $0 \Longleftrightarrow \tilde{\epsilon}<\frac{4}{12 y+1} \Longleftrightarrow \epsilon<\frac{4(1-y)}{8 y+1}$. Hence, when $\epsilon<\frac{4(1-y)}{8 y+1}$, all valuation types of the strategic-type buyer bid at most $\frac{2}{3}(1-y)+\frac{1}{4}$.

If $t_{b}$ is such that $\frac{2}{3} y+\frac{1}{12} \leq t_{b} \leq \frac{2}{3}(1-y)+\frac{1}{4}$, then the first order condition is,

$$
\frac{3}{2}\left(\frac{1-\tilde{\epsilon}}{1-y}+\tilde{\epsilon}\right)\left(v_{b}-\frac{3}{2} t_{b}+\frac{1}{8}\right)=\lambda_{1}-\lambda_{2}
$$

where $\lambda_{1}$ and $\lambda_{2}$ are the respective Lagrange multipliers for the two constraints, $t_{b} \leq \frac{2}{3}(1-y)+\frac{1}{4}$ and $\frac{2}{3} y+\frac{1}{12} \leq t_{b}$. It is now easy to conclude that $\forall v_{b} \in\left[y, \frac{5}{4}-y\right]$, bidding $\frac{2}{3} v_{b}+\frac{1}{12}$ is optimal.

(b) Suppose $\epsilon \geq \frac{4(1-y)}{8 y+1}$. The belief of the strategic-type buyer about the distribution of the seller's bid under the strategy specified in the lemma is:

- With probability $1-\tilde{\epsilon}$,

$$
G_{s}\left(t_{s}\right)=\left\{\begin{array}{cc}
0 & \text { if } t_{s}<\frac{1}{36}+\frac{2}{9 \tilde{\epsilon}} \\
\frac{3}{2(1-y)}\left(t_{s}-\frac{1}{36}-\frac{2}{9 \tilde{\epsilon}}\right) & \text { if } \frac{1}{36}+\frac{2}{9 \tilde{\epsilon}} \leq t_{s}<\frac{2}{3} y+\frac{1}{12} \\
\frac{y-\frac{1}{4}}{1-y} & \text { if } t_{s}=\frac{2}{3} y+\frac{1}{12} \\
\frac{3}{2(1-y)}\left(t_{s}-\frac{1}{4}\right) & \text { if } \frac{2}{3} y+\frac{1}{12} \leq t_{s} \leq \frac{2}{3}(1-y)+\frac{1}{4}
\end{array}\right.
$$

- With probability $\tilde{\epsilon}, t_{s}$ has the distribution function $\tilde{G}_{s}$.

Using arguments similar to those provided for proving part 2(a), it can be shown that no valuation type of the strategic-type buyer will ever bid below $\frac{2}{3} y+\frac{1}{12}$ and if the strategic-type buyer bids below $\frac{2}{3}(1-y)+\frac{1}{4}$, then she will bid $\frac{2}{3} v_{b}+\frac{1}{12}$. If the strategic-type buyer bids above $\frac{2}{3}(1-y)+\frac{1}{4}$, then the first order condition is the same as $(2)$ and therefore she will bid $\frac{2}{3} v_{b}+\frac{11}{36}-\frac{2}{9 \tilde{\epsilon}}$. One can also show that only valuation types of the strategic-type buyer with valuations above $\frac{11}{12}+\frac{1}{3 \tilde{\epsilon}}-y$ bid above $\frac{2}{3}(1-y)+\frac{1}{4}$ and all valuation types of the strategic-type buyer with valuations below $\frac{5}{4}-y$ bid below $\frac{2}{3}(1-y)+\frac{1}{4}$.

3. $y \geq \frac{5}{8}$ 
(a) Suppose $\epsilon<\frac{8(1-y)}{17-8 y}$. We prove that it is sequentially rational for the strategic-type players to bid according to the one-step equilibrium with price equal to $\frac{1}{2}$.

Given this strategy for the strategic-type seller, the strategic-type buyer's belief about the distribution of the seller's bid is:

- With probability $1-\tilde{\epsilon}, t_{s}=\frac{1}{2}$.

- With probability $\tilde{\epsilon}, t_{s}$ has the distribution function $\tilde{G}_{s}$.

If the strategic-type buyer bids less than $\frac{1}{2}$, then she can trade with only the behavioral-type seller. Then, since the behavioral-type seller bids according to the C-S* strategy, it is optimal for the strategic-type buyer to also bid according to the C-S* strategy, which is $\frac{2}{3} v_{b}+\frac{1}{12}$. However, $\frac{2}{3} v_{b}+\frac{1}{12}$ is less than $\frac{1}{2}$ only if $v_{b}<\frac{5}{8}$. Hence, bidding below $\frac{1}{2}$ is never a best response.

If the strategic-type buyer bids $t_{b} \geq \frac{1}{2}$, then the first order condition is the same as (2). Reasoning as in part 2(a) above, we get that all valuation types of the strategic-type buyer will bid equal to $\frac{1}{2}$ when $\epsilon<\frac{8(1-y)}{17-8 y}$.

(b) Suppose $\frac{8(1-y)}{17-8 y} \leq \epsilon \leq \frac{8(1-y)}{16 y-7}$. Given the strategies specified in the lemma, the belief of the strategic-type buyer about the distribution of the seller's bid is:

- With probability $1-\tilde{\epsilon}$ the seller is strategic type and therefore,

$$
G_{s}\left(t_{s}\right)=\left\{\begin{array}{cc}
0 & \text { if } t_{s}<\frac{1}{36}+\frac{2}{9 \tilde{\epsilon}} \\
\frac{3}{2(1-y)}\left(t_{s}-\frac{1}{36}-\frac{2}{9 \tilde{\epsilon}}\right) & \text { if } \frac{1}{36}+\frac{2}{9 \tilde{\epsilon}} \leq t_{s}<\frac{1}{2} \\
1 & \text { if } t_{s}=\frac{1}{2}
\end{array}\right.
$$

- With probability $\tilde{\epsilon}, t_{s}$ has the distribution function $\tilde{G}_{s}$.

With these beliefs, it is easy to show that since $v_{b} \geq \frac{5}{8}$, no valuation type of the strategic-type buyer will bid below $\frac{1}{2}$. If the strategic-type buyer bids $t_{b} \geq \frac{1}{2}$, then the first order condition is again the same as (2) and it can be easily checked that the strategy specified above is indeed the solution.

(c) Proof is similar to the proof of part $3(b)$.

Proof of Proposition 1: If all valuation types of the strategic-type players announce "Keen", then in the $[K, K]$ continuation game, it is sequentially rational for the strategic types to bid according to the C-S* equilibrium strategy as proved in Part 1 of Lemma 3. Any continuation game following the "Not Keen" announcement by one of the players is 
off-the-equilibrium path. In such a continuation game, it is sequentially rational for the strategic-type players to walk away from trade. Given these strategies in the continuation games, it is optimal for all valuation types of the strategic-type players to announce "Keen" in the cheap-talk stage.

We need the following two lemmas before proving that for small $\epsilon$ there exists a unique Monotonic-Symmetric- $\mathcal{R}^{*}$ equilibrium with $y \neq 0$.

Lemma 4 If $\epsilon<1$, then there does not exist a Monotonic-Symmetric- $\mathcal{R}^{*}$ equilibrium with $y \in\left(0, \frac{1}{4}\right]$.

Proof: Suppose $\epsilon<1$ and there exists a Monotonic-Symmetric- $\mathcal{R}^{*}$ equilibrium with $y \in$ $\left(0, \frac{1}{4}\right]$. Then $U_{b}(y,[K, K])=U_{b}(y,[K, N K])=0$, since in both the continuation games, the strategic-type buyer with valuation equal to $y$ trades with probability 0 . Whereas, $U_{b}(y,[N K, K])>0$ since in this continuation game, the strategic-type buyer with valuation $y$ trades with a positive probability. This contradicts the necessary condition (1).

Lemma 5 Suppose for some $\epsilon$ there exists a Monotonic-Symmetric- $\mathcal{R}^{*}$ equilibrium with $\frac{1}{4}<$ $y<\frac{5}{8}$. Then $\epsilon \geq \frac{4(1-y)}{8 y+1}$.

Proof: Suppose $\epsilon<\frac{4(1-y)}{8 y+1}$ and $\frac{1}{4}<y \leq \frac{4}{7}$. Applying Lemma 2 and Part 2(a) of Lemma 3 we get that,

- $U_{b}(y,[K, K] \mid s t)=\frac{\left(y-\frac{1}{4}\right)^{2}}{3(1-y)}$.

- $U_{b}(y,[K, N K])=0$.

- $U_{b}(y,[N K, K])=\frac{\left(y-\frac{y}{4}\right)^{2}}{2(1-y)}$.

- $U_{b}(y,[K, K] \mid b h)=\frac{1}{2}\left(y-\frac{1}{4}\right)^{2}$.

Putting these values in (1) and solving for $\epsilon$, we get:

$$
\epsilon=\frac{\frac{1}{2}\left(y-\frac{y}{4}\right)^{2}-\frac{1}{3}\left(y-\frac{1}{4}\right)^{2}}{\frac{1}{6}\left(y-\frac{1}{4}\right)^{2}+\frac{1}{2}\left(y-\frac{y}{4}\right)^{2}} .
$$

But this value of $\epsilon$ is greater than $\frac{4(1-y)}{8 y+1}$ for $y$ satisfying the inequality $\frac{1}{4}<y \leq \frac{4}{7}$.

Suppose $\epsilon<\frac{4(1-y)}{8 y+1}$ and $\frac{4}{7}<y<\frac{5}{8}$. Again, applying Lemma 2 and Part 2(a) of Lemma 3 we get that,

- $U_{b}(y,[K, K] \mid s t)=\frac{\left(y-\frac{1}{4}\right)^{2}}{3(1-y)}$. 
- $U_{b}(y,[K, N K])=\frac{\left(\frac{7 y}{4}-1\right)^{2}}{3 y}$.

- $U_{b}(y,[N K, K])=\left(\frac{5 y}{4}-\frac{1}{2}\right)$.

- $U_{b}(y,[K, K] \mid b h)=\frac{1}{2}\left(y-\frac{1}{4}\right)^{2}$.

Again, putting these values in (1) and solving for $\epsilon$, we get:

$$
\epsilon=\frac{\frac{1}{3}\left(y-\frac{1}{4}\right)^{2}+\frac{1}{3}\left(\frac{7 y}{4}-1\right)^{2}-(1-y)\left(\frac{5 y}{4}-\frac{1}{2}\right)}{\frac{1}{3}\left(y-\frac{1}{4}\right)^{2}+\frac{1}{3}\left(\frac{7 y}{4}-1\right)^{2}-(1-y)\left(\frac{5 y}{4}-\frac{1}{2}\right)-\frac{1}{2}\left(y-\frac{1}{4}\right)^{2}} .
$$

But this value of $\epsilon$ is greater than $\frac{4(1-y)}{8 y+1}$ for $y$ satisfying the inequality $\frac{4}{7}<y<\frac{5}{8}$.

Proof of Proposition 2: Pick an $\epsilon \in\left(0, \frac{244-36 \sqrt{5}}{829}\right)$. From Lemma 4, we know that for this $\epsilon$, there cannot exist a Monotonic-Symmetric- $\mathcal{R}^{*}$ equilibrium with $0<y \leq \frac{1}{4}$. Also, this value of $\epsilon$ is less than $\frac{4(1-y)}{8 y+1} \forall y$ s.t. $\frac{1}{4}<y<\frac{5}{8}$. Hence, from Lemma 5 , there cannot exist a Monotonic-Symmetric- $\mathcal{R}^{*}$ equilibrium with $y$ such that $\frac{1}{4}<y<\frac{5}{8}$.

Suppose for this value of $\epsilon$ there exists a Monotonic-Symmetric- $\mathcal{R}^{*}$ equilibrium with $y \geq \frac{5}{8}$ and $\frac{8(1-y)}{17-8 y} \leq \epsilon \leq \frac{8(1-y)}{16 y-7}$. Since $\frac{8(1-y)}{17-8 y} \geq \frac{244-36 \sqrt{5}}{829}$ for $y$ such that $\frac{5}{8} \leq y \leq \frac{5+\sqrt{5}}{10}$, it must be the case that $y>\frac{5+\sqrt{5}}{10}$. For such a $y$ to be a Monotonic-Symmetric- $\mathcal{R}^{*}$ equilibrium, it must satisfy the necessary condition (1), which in this case reduces to:

$$
\begin{aligned}
& (1-\epsilon)\left(y-\frac{55}{144}-\frac{\epsilon+(1-\epsilon)(1-y)}{18 \epsilon}\right)\left(\frac{17}{24}-\frac{\epsilon+(1-\epsilon)(1-y)}{3 \epsilon}\right) \\
+ & (1-\epsilon)\left(\left(y-\frac{1}{2}\right)\left(\frac{7}{24}+\frac{\epsilon+(1-\epsilon)(1-y)}{3 \epsilon}-y\right)-(1-y)\left(\frac{5 y}{4}-\frac{1}{2}\right)\right) \\
+ & \frac{(1-\epsilon)}{3}\left(\frac{7 y}{4}-1\right)^{2}+\frac{3 \epsilon}{8}\left(y-\frac{7}{16}\right)=0 .
\end{aligned}
$$

It can, however, be shown that there does not exist a $y>\frac{5+\sqrt{5}}{10}$ with $\frac{8(1-y)}{17-8 y} \leq \epsilon$ that satisfies the above necessary condition.

Finally, suppose that for this value of $\epsilon$ there exists a Monotonic-Symmetric- $\mathcal{R}^{*}$ equilibrium with $y \geq \frac{5}{8}$ and $\epsilon>\frac{8(1-y)}{16 y-7}$. The necessary condition for such a value of $y$ to be a Monotonic-Symmetric- $\mathcal{R}^{*}$ equilibrium is:

$$
\begin{aligned}
& (1-\epsilon)\left(\frac{1}{3}(1-y)\left(\frac{5 y}{2}-1\right)+\frac{1}{3}\left(\frac{7 y}{4}-1\right)^{2}-(1-y)\left(\frac{5 y}{4}-\frac{1}{2}\right)\right) \\
+ & \frac{\epsilon}{2}\left(y-\frac{7}{12}+\frac{\epsilon+(1-\epsilon)(1-y)}{3 \epsilon}\right)\left(y+\frac{1}{12}-\frac{\epsilon+(1-\epsilon)(1-y)}{3 \epsilon}\right)=0 .
\end{aligned}
$$


Again, it can be shown that there does not exist a $y \geq \frac{5}{8}$ that satisfies the necessary condition and also $\epsilon>\frac{8(1-y)}{16 y-7}$.

Therefore, if there exists a Monotonic-Symmetric- $\mathcal{R}^{*}$ equilibrium with $y \neq 0$ for $\epsilon \epsilon$ $\left(0, \frac{244-36 \sqrt{5}}{829}\right)$, it must be such that $y \geq \frac{5}{8}$ and $\epsilon<\frac{8(1-y)}{17-8 y}$. Under these conditions, $y$ must solve the necessary condition (1), which is now,

$$
\epsilon=\frac{\left(y-\frac{1}{2}\right)(1-y)+\frac{1}{3}\left(\frac{7 y}{4}-1\right)^{2}-(1-y)\left(\frac{5 y}{4}-\frac{1}{2}\right)}{\left(y-\frac{1}{2}\right)(1-y)+\frac{1}{3}\left(\frac{7 y}{4}-1\right)^{2}-(1-y)\left(\frac{5 y}{4}-\frac{1}{2}\right)-\frac{3}{8}\left(y-\frac{7}{16}\right)}
$$

The right-hand side of the above equation is a continuous and strictly decreasing function for $y \in\left[\frac{5}{8}, 1\right]$. Also, the right-hand side converges to $\frac{244-36 \sqrt{5}}{829}$ as $y \rightarrow \frac{5+\sqrt{5}}{10}$ and to 0 as $y \rightarrow \frac{34+6 \sqrt{5}}{61}$. Hence $\forall \epsilon \in\left(0, \frac{244-36 \sqrt{5}}{829}\right)$, there exists a unique $y_{\epsilon}$ that solves the above condition. It is easy to check that $\epsilon<\frac{8\left(1-y_{\epsilon}\right)}{17-8 y_{\epsilon}}$. Therefore, there can exist at most one Monotonic-Symmetric- $\mathcal{R}^{*}$ equilibrium with $y \neq 0$ for this value of $\epsilon$.

Now we prove that for this $\epsilon$ we have a Monotonic-Symmetric- $\mathcal{R}^{*}$ equilibrium with $y=y_{\epsilon}$.

Consider the following strategies (We are not specifying the off-the-equilibrium path bids of the strategic types since the proof does not require their exact values.):

1. For the strategic-type buyer:

- In the cheap-talk stage say "Keen" if $v_{b} \geq y_{\epsilon}$; otherwise, say "Not Keen".

- In the continuation game $[K, K]$, if $v_{b} \geq y_{\epsilon}$, then bid $\frac{1}{2}$.

- In the continuation game $[K, N K]$, if $v_{b} \geq y_{\epsilon}$, then bid according to the C-S equilibrium strategy for the $\frac{1}{2}$-double auction when the valuations of the buyer and seller are distributed uniformly and independently on $\left[y_{\epsilon}, 1\right]$ and $\left[1-y_{\epsilon}, 1\right]$ respectively.

- In the continuation game $[N K, K]$, if $v_{b}<y_{\epsilon}$, then bid according to the C-S equilibrium strategy for the $\frac{1}{2}$-double auction when the valuations of the buyer and seller are distributed uniformly and independently on $\left[0, y_{\epsilon}\right]$ and $\left[0,1-y_{\epsilon}\right]$ respectively.

2. For the strategic-type seller:

- In the cheap-talk stage say "Keen" if $v_{s} \leq 1-y_{\epsilon}$; otherwise, say "Not Keen".

- In the continuation game $[K, K]$, if $v_{s} \leq 1-y_{\epsilon}$, then bid $\frac{1}{2}$. 
- In the continuation game $[K, N K]$, if $v_{s}>1-y_{\epsilon}$, then bid according to the C-S equilibrium strategy for the $\frac{1}{2}$-double auction when the valuations of the buyer and seller are distributed uniformly and independently on $\left[y_{\epsilon}, 1\right]$ and $\left[1-y_{\epsilon}, 1\right]$ respectively.

- In the continuation game $[N K, K]$, if $y \leq 1-y_{\epsilon}$, then bid according to the C-S equilibrium strategy for the $\frac{1}{2}$-double auction when the valuations of the buyer and seller are distributed uniformly and independently on $\left[0, y_{\epsilon}\right]$ and $\left[0,1-y_{\epsilon}\right]$ respectively.

Since $\epsilon<\frac{8\left(1-y_{\epsilon}\right)}{17-8 y_{\epsilon}}$, using Lemma 3.3(a), we get that the strategic-type players' strategies are sequentially rational in the continuation game $[K, K]$. Lemma 2 shows that the strategictype players' strategies are sequentially rational in the continuation games $[K, N K]$ and $[N K, K]$.

To prove that these strategies form an equilibrium, we show that there does not exist a profitable deviation in the cheap-talk stage. Define,

$$
\begin{aligned}
D\left(v_{b}\right)= & \left((1-\epsilon)\left(1-y_{\epsilon}\right)+\epsilon\right) U_{b}\left(v_{b},[K, K]\right)+(1-\epsilon) y_{\epsilon} U_{b}\left(v_{b},[K, N K]\right) \\
& -(1-\epsilon)\left(1-y_{\epsilon}\right) U_{b}\left(v_{b},[N K, K]\right)
\end{aligned}
$$

to be the gain that the strategic-type buyer with valuation $v_{b}$ receives from saying "Keen" instead of "Not Keen" in the first stage and then playing optimally in the bargaining stage given the seller's strategy. We prove that $D\left(v_{b}\right) \leq 0$ for $v_{b} \leq y_{\epsilon}$ and $D\left(v_{b}\right) \geq 0$ for $v_{b} \geq y_{\epsilon}$, which implies that there does not exist a profitable deviation for any valuation type of the strategic-type buyer in the cheap-talk stage.

In the continuation game $[K, K]$, no valuation type of the strategic-type buyer will bid above $\frac{1}{2}$ (see the proof of Part 3(a) of Lemma 3). Also, all valuation types of the strategictype buyer with valuations less than $\frac{1}{4}$ do not trade in this continuation game since the lowest bid by the seller in this continuation game is $\frac{1}{4}$. Moreover, if the strategic-type buyer with valuation $v_{b} \geq \frac{1}{4}$ bids below $\frac{1}{2}$, then she must bid equal to $\frac{2}{3} v_{b}+\frac{1}{12}$ because she can then trade only with the behavioral-type seller. The latter fact implies that only valuation types of the strategic-type buyer with valuations below $\frac{5}{8}$ could possibly bid below $\frac{1}{2}$.

First, we prove that in the $[K, K]$ continuation game, there exists a valuation type of the strategic-type buyer with valuation $\hat{v}_{b} \in\left(\frac{1}{2}, \frac{5}{8}\right)$ who is indifferent between bidding $\frac{1}{2}$ and $\frac{2}{3} \hat{v}_{b}+\frac{1}{12}$ and all valuation types of the strategic-type buyer with valuations in the interval $\left[\frac{1}{4}, \hat{v}_{b}\right)$ bid below $\frac{1}{2}$ and all valuation types of the strategic-type buyer with valuations above $\hat{v}_{b}$ 
bid $\frac{1}{2}$. If the strategic-type buyer bids $\frac{1}{2}$, then her expected payoff is $(1-\tilde{\epsilon})\left(v_{b}-\frac{1}{2}\right)+\tilde{\epsilon} \frac{3}{8}\left(v_{b}-\frac{7}{16}\right)$. If the strategic-type buyer with $v_{b} \geq \frac{1}{4}$ bids $\frac{2}{3} v_{b}+\frac{1}{12}$, then her expected payoff is $\tilde{\epsilon} \frac{1}{2}\left(v_{b}-\frac{1}{4}\right)^{2}$. $\hat{v}_{b}$ is defined by the $v_{b}$ that solves,

$$
f\left(v_{b}\right) \equiv(1-\tilde{\epsilon})\left(v_{b}-\frac{1}{2}\right)+\tilde{\epsilon}\left(\frac{3}{8}\left(v_{b}-\frac{7}{16}\right)-\frac{1}{2}\left(v_{b}-\frac{1}{4}\right)^{2}\right)=0 .
$$

The result follows from the facts that $f\left(\frac{1}{2}\right)<0, f\left(\frac{5}{8}\right)>0$ and $f^{\prime}>0$ if $v_{b}<\frac{5}{8}$. Note that, $\hat{v}_{b}=\frac{5}{8}+\frac{(1-\epsilon)\left(1-y_{\epsilon}\right)}{\epsilon}-\frac{\sqrt{(1-\epsilon)\left(1-y_{\epsilon}\right)\left(\epsilon+4(1-\epsilon)\left(1-y_{\epsilon}\right)\right)}}{2 \epsilon}$.

Second, we prove that $D\left(v_{b}\right) \leq 0$ if $v_{b} \leq \hat{v}_{b}$. Since $v_{b} \leq \hat{v}_{b}<\frac{5}{8}, U_{b}\left(v_{b},[K, N K]\right)=0$ because the lowest bid in the $[K, N K]$ continuation game is $\frac{5 y_{\epsilon}}{12}+\frac{1}{3}$ which is greater than $\frac{5}{8}$ as $y_{\epsilon}>0.7$. Also,

$$
U_{b}\left(v_{b},[K, K]\right)=\left\{\begin{array}{cl}
0 & \text { if } v_{b} \leq \frac{1}{4} \\
\tilde{\epsilon} \frac{1}{2}\left(v_{b}-\frac{1}{4}\right)^{2} & \text { if } \frac{1}{4}<v_{b} \leq \hat{v}_{b} \\
(1-\tilde{\epsilon})\left(v_{b}-\frac{1}{2}\right)+\tilde{\epsilon} \frac{3}{8}\left(v_{b}-\frac{7}{16}\right) & \text { if } v_{b}>\hat{v}_{b}
\end{array}\right.
$$

Finally,

$$
U_{b}\left(v_{b},[N K, K]\right)=\left\{\begin{array}{cc}
0 & \text { if } v_{b} \leq \frac{y_{\epsilon}}{4} \\
\frac{1}{2} \frac{\left(v_{b}-\frac{y_{\epsilon}}{4}\right)^{2}}{1-y_{\epsilon}} & \text { if } \frac{y_{\epsilon}}{4}<v_{b} \leq 1-\frac{3 y_{\epsilon}}{4} \\
v_{b}-\left(1-\frac{3 y_{\epsilon}}{4}\right)+\frac{1}{2}\left(1-y_{\epsilon}\right) & \text { if } v_{b}>1-\frac{3 y_{\epsilon}}{4}
\end{array}\right.
$$

So $\forall v_{b} \leq \frac{y_{\epsilon}}{4}$, all terms on the right-hand side of (5) are 0 and hence $D\left(v_{b}\right)=0$.

For $v_{b} \in\left(\frac{y_{\epsilon}}{4}, \frac{1}{4}\right], D\left(v_{b}\right)=-(1-\epsilon) \frac{1}{2}\left(v_{b}-\frac{y_{\epsilon}}{4}\right)^{2}<0$. For $v_{b} \in\left(\frac{1}{4}, 1-\frac{3 y_{\epsilon}}{4}\right]$,

$$
D\left(v_{b}\right)=\frac{1}{2}\left(\epsilon\left(v_{b}-\frac{1}{4}\right)^{2}-(1-\epsilon)\left(v_{b}-\frac{y_{\epsilon}}{4}\right)^{2}\right)<\frac{1}{2}\left(v_{b}-\frac{y_{\epsilon}}{4}\right)^{2}(\epsilon-(1-\epsilon))<0
$$

because $\epsilon<\frac{1}{2}$.

Next, we show that $D^{\prime}\left(v_{b}\right)<0, \forall v_{b} \in\left(1-\frac{3 y_{\epsilon}}{4}, \hat{v}_{b}\right) .{ }^{15}$ For $v_{b} \in\left(1-\frac{3 y_{\epsilon}}{4}, \hat{v}_{b}\right)$,

$$
D\left(v_{b}\right)=\frac{1}{2} \epsilon\left(v_{b}-\frac{1}{4}\right)^{2}-(1-\epsilon)\left(1-y_{\epsilon}\right)\left(v_{b}-\left(1-\frac{3 y_{\epsilon}}{4}\right)+\frac{1}{2}\left(1-y_{\epsilon}\right)\right) .
$$

${ }^{15}$ Note that $1-\frac{3 y_{\epsilon}}{4}<\frac{1}{2}<\hat{v}_{b}$ because $y_{\epsilon}>\frac{2}{3}$. 
Therefore,

$$
\begin{aligned}
D^{\prime}\left(v_{b}\right) & =\epsilon\left(v_{b}-\frac{1}{4}\right)-(1-\epsilon)\left(1-y_{\epsilon}\right) \\
& <\epsilon\left(\frac{5}{8}-\frac{1}{4}\right)-(1-\epsilon)\left(1-y_{\epsilon}\right)=\frac{3}{8} \epsilon-(1-\epsilon)\left(1-y_{\epsilon}\right) .
\end{aligned}
$$

The last term is negative whenever $\epsilon<\frac{8\left(1-y_{\epsilon}\right)}{11-8 y_{\epsilon}}$. The result follows from the fact that $\epsilon<$ $\frac{8\left(1-y_{\epsilon}\right)}{17-8 y_{\epsilon}}<\frac{8\left(1-y_{\epsilon}\right)}{11-8 y_{\epsilon}}$. Since $D\left(v_{b}\right) \leq 0 \forall v_{b} \in\left[0,1-\frac{3 y}{4}\right], D^{\prime}\left(v_{b}\right)<0 \forall v_{b} \in\left(1-\frac{3 y}{4}, \hat{v}_{b}\right)$ and $D\left(v_{b}\right)$ is a continuous on $\left[0, \hat{v}_{b}\right]$, we get the result that $D\left(v_{b}\right) \leq 0 \forall v_{b} \leq \hat{v}_{b}$.

Lastly, we prove that $D^{\prime}\left(v_{b}\right)>0 \forall v_{b}>\hat{v}_{b}$. The derivative of the first term is equal to $(1-\epsilon)\left(1-y_{\epsilon}\right)+\frac{3}{8} \epsilon$. The derivative of the second term is non-negative since, by the envelope theorem, it is equals $(1-\epsilon) y_{\epsilon}$ (Probability of trading). Finally, the derivative of the last term is $-(1-\epsilon)\left(1-y_{\epsilon}\right)$. Hence for $v_{b}>\hat{v}_{b}$,

$$
D^{\prime}\left(v_{b}\right)=\frac{3}{8} \epsilon+(1-\epsilon) y_{\epsilon}(\text { Probability of trading })>0
$$

From the above two results, that is, $D\left(v_{b}\right) \leq 0$ if $v_{b} \leq \hat{v}_{b}$ and $D^{\prime}\left(v_{b}\right)>0 \forall v_{b}>\hat{v}_{b}$, and the facts that $D\left(y_{\epsilon}\right)=0$ and $y_{\epsilon}>\hat{v}_{b}$ we get the result that $D\left(v_{b}\right) \leq 0$ for $v_{b} \leq y_{\epsilon}$ and $D\left(v_{b}\right) \geq 0$ for $v_{b} \geq y_{\epsilon}$.

Proof of Proposition 6: From Lemma 4, we know that if $\epsilon<1$, then there does not exist a Monotonic-Symmetric- $\mathcal{R}^{*}$ equilibrium with $0<y \leq \frac{1}{4}$.

Also, for $\epsilon \in\left[\frac{244-36 \sqrt{5}}{829}, 1\right)$ there cannot exist a Monotonic-Symmetric- $\mathcal{R}^{*}$ equilibrium with $y \geq \frac{3}{4}$. Pick an $\epsilon \in\left[\frac{244-36 \sqrt{5}}{829}, 1\right)$. Suppose there exists a Monotonic-Symmetric- $\mathcal{R}^{*}$ equilibrium with $y \geq \frac{3}{4}$. In addition, suppose that $\epsilon<\frac{8(1-y)}{17-8 y}$. But this cannot happen because $\frac{8(1-y)}{17-8 y}=\frac{244-36 \sqrt{5}}{829}$ when $y=\frac{5+\sqrt{5}}{10}<\frac{3}{4}$ and $\frac{8(1-y)}{17-8 y}$ is a decreasing function between $[0,1]$. So instead, suppose that $\frac{8(1-y)}{17-8 y} \leq \epsilon \leq \frac{8(1-y)}{16 y-7}$. Then the pair $(y, \epsilon)$ must satisfy the necessary condition (3). But again, it can be shown that there does not exist a $y \geq \frac{3}{4}$ and $\epsilon \in\left[\frac{244-36 \sqrt{5}}{829}, 1\right)$ that satisfies the necessary condition. Finally, suppose that $\epsilon>\frac{8(1-y)}{16 y-7}$. In this case, the necessary condition for the pair $(y, \epsilon)$ to be a Monotonic-Symmetric- $\mathcal{R}^{*}$ equilibrium is (4). However, no such pair $(y, \epsilon)$ with $y \geq \frac{3}{4}$ and $\epsilon \in\left[\frac{244-36 \sqrt{5}}{829}, 1\right)$ exists.

To complete the proof, note that for any Monotonic-Symmetric- $\mathcal{R}^{*}$ equilibrium, the exante probability of trade in the event that both players are strategic type is greater than the ex-ante probability of trade in the C-S* equilibrium if $y \in\left(\frac{1}{4}, \frac{3}{4}\right)$. Suppose $\frac{1}{4}<y \leq \frac{4}{7}$, then the ex-ante probability of trade in the event that both players are strategic type is $\frac{9}{32}+\frac{1}{4}(1-y)\left(\frac{7}{4} y-\frac{1}{4}\right)$, which is greater than $\frac{9}{32}$ for all such $y$. If $\frac{4}{7}<y<\frac{5}{8}$, then the ex-ante 
probability of trade among the strategic types is $\frac{1}{2}\left(1-\frac{y}{4}\right)^{2}-\frac{1}{2}\left(\frac{7}{4} y-1\right)^{2}-\frac{1}{2}\left(\frac{5}{4}-2 y\right)^{2}$, which is greater than $\frac{9}{32}$ for this range of $y$. Finally, if $\frac{5}{8} \leq y<\frac{3}{4}$, then the ex-ante probability of trade in the event that both players are strategic type is given by $\frac{3}{2} y(1-y)$, which is also greater than $\frac{9}{32}$.

\section{References}

Abreu D, Gul F (2000) Bargaining and reputation. Econometrica 68: 85-117

Ausubel L, Cramton P, Deneckere R (2002) Bargaining with incomplete information. In: Aumann R, Hart S (eds.) Handbook of game theory with economic applications 3. NorthHolland, Amsterdam, 1897-1946

Binmore K, Osborne M, Rubinstein A (1992) Noncooperative models of bargaining. In: Aumann R, Hart S (eds.) Handbook of game theory with economic applications 1. NorthHolland, Amsterdam, 179-225

Chatterjee K, Samuelson W (1983) Bargaining under incomplete information. Operations Research 31: 835-851

Farrell J, Gibbons R (1989) Cheap talk can matter in bargaining. J Econ Theory 48: 221-237

Kennan J, Wilson R (1993) Bargaining with private information. J Econ Lit XXXI: 45-104

Kreps D, Milgrom P, Roberts J, Wilson R (1982) Rational cooperation in the finitely repeated Prisoner's Dilemma. J Econ Theory 27: 245-252

Kreps D, Wilson R (1982) Reputation and imperfect information. J Econ Theory 27: 253-279

Leininger W, Linhart P, Radner R (1989) Equilibria of the sealed-bid mechanism for bargaining with incomplete information. J Econ Theory 48: 63-106

McGinn K, Thompson L, Bazerman M (2003) Dyadic processes of disclosure and reciprocity in bargaining with communication. Journal of Behavioral Decision Making 16: 17-34

Milgrom P, Roberts J (1982) Predation, reputation and entry deterrence. J Econ Theory 27: 280-312

Myerson R, Satterthwaite M (1983) Efficient mechanisms for bilateral trading. J Econ Theory 29: $265-281$ 
Osborne M, Rubinstein A (1990) Bargaining and markets. Academic Press, San Diego

Radner R, Schotter A (1989) The sealed-bid mechanism: an experimental study. J Econ Theory 48: 179-220

Satterthwaite M, Williams S (1989) Bilateral trade with the sealed bid $k$-double auction: existence and efficiency. J Econ Theory 48: 107-133

Serrano R (2005) Bargaining. In: Durlauf S, Blume L (eds.) The new Palgrave dictionary of economics 2. McMillan, London, Forthcoming

Sobel J (1985) A theory of credibility. Rev Econ Stud LII: 557-573

Valley K, Thompson L, Gibbons R, Bazerman M (2002) How communication improves efficiency in bargaining games. Games Econ Behav 38: 127-155 